\title{
The Dynamics of Institutional Pressures and Stakeholder Behavior in National EHR Implementations: A Tale of Two Countries
}

\author{
Ela Klecun ${ }^{1}$, Ya Zhou ${ }^{2}$, Atreyi Kankanhalli ${ }^{3}$, Yap Hwee Wee ${ }^{3}$ and Ralph Hibberd ${ }^{1}$ \\ ${ }^{1}$ London School of Economics and Political Science, UK \\ ${ }^{2}$ The University of Nottingham Ningbo China, China \\ ${ }^{3}$ National University of Singapore, Singapore
}

Cite as: Klecun, E., Zhou, Y., Kankanhalli, A., Wee, Y. H., \& Hibberd, R. (2019). The dynamics of institutional pressures and stakeholder behavior in national electronic health record implementations: A tale of two countries. Journal of Information Technology. Online first https://doi.org/10.1177/0268396218822478

\begin{abstract}
Through electronic health records (EHRs) implementation, national healthcare systems are aiming for care integration and enhancement, as a response to the significant challenges of ageing populations, increasing chronic disease burdens, and rising costs. However, the path to large-scale EHR implementation is seldom smooth, involving multiple stakeholders with diverse interests and influences. This study proposes a framework that draws on both stakeholder and institutional theories to understand the complex dynamics of stakeholder interactions and institutional pressures over time during EHR systems implementation. This framework is utilized to analyze the national EHR programs of Singapore and England, which provide contrasting perspectives on how two top-down system implementations took place with different outcomes. Our results suggest that in the Singapore case the presence of boundary spanners, supporting implementation agency that included IT staff from healthcare organizations, and greater engagement with medical professionals, were associated with more positive dynamics of stakeholder interactions (e.g., limited pushback from professionals or the press) during EHR implementation than in England. Differences in the healthcare structures and systems, EHR project organization, and the combined influences of institutional pressures shed light on the varying implementation paths and outcomes in the two cases. This study adds to the HIT literature through a comparative examination of the organizational and social processes during complex national healthcare integration projects. It also contributes to the institutional and stakeholder literatures in several ways, in particular by depicting the processes and outcomes of the dynamics of isomorphic pressures played out under different institutional conditions. Last, our proposed framework provides a useful conceptual tool for analyzing such complex IT implementations across multiple stakeholders.
\end{abstract}

Keywords: Electronic health records (EHRs), health information technology (HIT), stakeholder attributes, institutional pressures, Singapore, England 
Dynamics of pressures in national EHR implementations 


\section{INTRODUCTION}

In recent years, developed economies have witnessed growing healthcare costs as both average life expectancy and chronic disease burdens increase, costs which are expected to rise substantially by 2060 (OECD, 2013). These challenges are exacerbated by the fragmentation in many nations' healthcare systems, which is manifest in poor care coordination (Bauchner et al., 2016). In response to these concerns, many nations including Singapore, the United Kingdom (UK), Japan and the United States (US) have examined the use of electronic health records (EHRs) as a means to enhance care (AcademyHealth 2010). EHRs, defined as longitudinal electronic records of patient health information, can act as a foundation for healthcare integration, where records follow established standards, are available and can be shared. Unlike Electronic Medical Records (EMRs), which are not designed to be shared outside the individual practice, EHR can provide an integrated view of a patient's health history supporting care across organizational boundaries (AHRQ, 2014), and potentially improve healthcare efficiency and quality (Currie et al., 2011). Cost efficiencies might also be achieved through economies of scale realized through EHR use (Baxter \& Lewis, 2010). Aggregated national EHR data could also support developments of pharmaceutical drugs and therapies (Kohli and Tan, 2016).

Given the expected benefits, healthcare providers have been subject to institutional pressures from national governments to implement EHRs. This is the case in England (Klecun, 2016), Singapore (Kwee, 2009), and the US (Fareed et al., 2015; Sherer et al., 2016). In England, the National Programme for IT (NPfIT) attempted to implement an EHR solution to cover all 50 million citizens (Syal, 2013). In Singapore's national EHR program, the government has involved 280 healthcare institutions and 14,000 clinicians to support EHR delivery ${ }^{1}$.

Achieving healthcare integration through EHR implementation is difficult. England's efforts towards integration through health informatics have had little effect on process and service fragmentation (Currie, 2013). Similarly, US efforts from 2007 to 2015 have only yielded 50\% of meaningful physician EHR use. These difficulties have been attributed to a range of issues including inadequate stakeholder engagement (Shirey, 2012), poor communication (Brodbeck, 2012) and misalignment of interests (Jackson et al., 2008). Whilst previous studies have attempted to understand these problems (e.g. Yeow and Faraj, 2011) the organizational perspective taken by many of those (e.g. Hung et al., 2014), does not easily translate to the case of regional and national EHRs. The latter involve coordination of multiple stakeholders across organizations and regions.

Achieving healthcare integration calls on vertical consolidation across primary, secondary and tertiary care, as well as horizontal integration across health, community and social care. This suggests a

\footnotetext{
${ }^{1}$ http://www.channelnewsasia.com/news/health/it-helping-to-address/1362576.html
} 
range of stakeholders in development and implementation of EHR, and points to the importance of examining the dynamics of their participation. Prior work has looked at the organizational and social processes involved in service deployment (Currie \& Finnegan, 2009), and the changing roles and perceptions of stakeholders in nation-wide HIT implementation (Pouloudi et al., 2016). Building on this literature, we further explore the interactions and influences of stakeholders in EHR implementations and the manner in which these dynamics shape deployment.

To provide insights from different national programs we examine two EHR implementations, Singapore's National Electronic Healthcare Record (NEHR) and the NPfIT National Care Records Service (NCRS) in England. Other than their clear differences in terms of size, the two countries exhibit both similarities and differences in their healthcare structures, systems, and EHR implementations, which enables us to gain a better understanding of the target phenomenon. In both countries most tertiary healthcare services are provided by public hospitals and thus these were the key stakeholders in EHR implementations. The other important stakeholder, primary care, has evolved differently in England and Singapore, England having public provision supported by large scale Electronic Patient Records deployment and Singapore having largely private provision and mainly paper-based clinical systems. In both countries, there were coordinating public agencies responsible for healthcare assets and national EHR programs, enforcing a "top-down" implementation model. However, despite their similarities, the two programs unfolded differently, drawing in distinct stakeholder groups, involving dissimilar dynamics of institutional pressures and stakeholder interactions. Thus, these two programs provide us with a valuable opportunity to contrast "top-down" implementations of the national EHR programs in different contexts and having varied outcomes.

Motivated thus, we propose the following research question: How do stakeholder interactions shape EHR implementation in different national contexts? Specifically, we aim to examine: (a) What are the significant stakeholders and groups in EHR implementations in Singapore and England? (b) How do the dynamics of their interactions, and pressures they exert and experience play out over time? (c) How do institutional contexts and project organization influence those interactions? To address these questions in our study, we: 1) Identify the key stakeholders and analyze their attributes, to better understand how they might shape the implementation of EHRs, 2) Examine the dynamics of stakeholders' interactions over time in realizing EHRs, focusing on stakeholder power, interests, institutional pressures, and logics.

We conducted interpretive case studies using a new analytical framework we derived from stakeholder and institutional theory. Stakeholder theory (Mitchell et al., 1997; Freeman, 2010) is relevant for our study given complex systems, such as EHR, involve broad, heterogeneous parties (Pouloudi et al., 2016). It supports identification and analysis of these. Institutional theory (DiMaggio \& Powell, 1983) has been employed in information systems literature to understand forces affecting technology development, 
innovation and adoption (Mignerat \& Rivard, 2009). It supports our analysis of the evolution of the institutional environment and actors' responses to these changes. Taken together, the two theories inform longitudinal examination of EHR implementation in an environment characterized by multiple stakeholders' dynamic interactions.

The theoretical contribution of this study is through an extension of our understanding of how stakeholders, with different attributes and institutional logics interact through exerted and experienced pressures in the context of national EHR deployments. Our identification of key stakeholder groupings and interactions contributes to research on stakeholders. We also advance the institutional literature by identifying the dynamics of pressures amongst stakeholders during implementation. The comparison of the two case studies supports better understanding of how these dynamics led to different outcomes. Practically, this study should support practitioners in understanding and managing stakeholder dynamics in EHR implementations.

In the following sections we describe stakeholder and institutional theories and the integrative framework that we apply to the analysis of the two national EHR implementations. We then compare the two programs and present our conclusions, elaborating on the contributions highlighted above.

\section{CONCEPTUAL BACKGROUND AND AN INTEGRATIVE FRAMEWORK}

\subsection{Institutional Theory and Institutional Logics}

Institutional theory describes the process by which institutional structures, defined as systems of embedded social rules and norms (Hodgson, 2006), become established as guidelines for individual and organizational action, and how they may evolve or decline over time (Scott, 2005). Healthcare organizations, including hospitals and professional bodies, represent institutions which together constitute an institutional field (Currie \& Guah, 2007). Institutional behaviors emerge from inter-related processes at the individual, organization and inter-organizational level (Marchington \& Vincent, 2004). For example, at the individual level, it is managers' norms and values that account for institutionalized behaviors. In healthcare, doctors represent individual participants in institutionalization. Their behaviors and knowledge are shaped by institutions, such as medical schools, which promote professionalization. In turn, doctors' collective struggle for professional autonomy enables them to influence institutional formation and change (Oliver, 1991). At an organizational level, organizational structures, shared belief systems and political pressures generate institutional structures which influence behaviors. At the inter-organizational level, pressures from government, industry alliances and from societal expectations influence actors' behaviors as they seek legitimacy and support (DiMaggio \& Powell, 1983).

Institutional theorists have argued that over time, institutional actors, (i.e. organizations) in similar environments will show convergence in behaviors as a result of isomorphism (Hawley, 1968). DiMaggio 
and Powell (1983) suggested that isomorphism arose through the operation of three forms of pressure, coercive, mimetic and normative. Coercive pressure is exerted by those entities that have resources the institutional actor relies upon, such as the reliance of Singapore's hospitals on funding from Ministry of Health Holdings (MOHH) which creates pressure to adhere to Ministry of Health (MOH) regulation. Government regulations and standards are examples of direct and strong pressures, whilst incentives can be considered as direct and soft pressures. Cultural expectations can also be viewed as a form of indirect coercive pressure. Mimetic pressure refers to institutional actors' adoption of structures, practices and technologies because these are viewed as best practice without questioning their legitimacy and claims (Oliver, 1991). Institutions are more likely to exhibit mimetic behavior under conditions of uncertainty, e.g., when faced with new technological innovations. In healthcare, adoption of EHR has been inspired by the benefits ascribed to EHR at Kaiser Permanente (Chen et al., 2009). Normative pressure emerges primarily from professionalization, the collective struggle of members of an occupation to define the conditions and methods of work and to establish a knowledge base that legitimizes occupational autonomy (DiMaggio \& Powell, 1983). This may include perceptions of how HIT should be introduced. In the case of EHR, where systems are viewed as limiting professional autonomy or disrupting legitimized practice, normative pressure might be applied to influence EHR development. In England this was manifest in debates, led by the physicians union the British Medical Association, over privacy risks posed by EHRs (Campion-Awaad et al., 2014; Pouloudi et al., 2016). Normative pressures might also be directed towards members of a profession through expectations that standards and practices inculcated in training would be followed. In our study we are concerned with coercive, mimetic and normative pressures exerted by varied stakeholders, and we examine mimetic behavior at national, organizational and group levels.

Through these pressures, certain norms, patterns of behavior, and ideas become institutionalized and become the principles, or institutional logics, for the field. Institutional logics shape the way institutions are organized, roles and identities are defined and performed, and actors behave, e.g., towards a new IT system. However, stakeholders have the capacity to reflect upon and modify these logics (Lockett et al., 2012). Different, potentially incompatible, institutional logics might co-exist in an organization, creating strategic challenges for the organization (Pache \& Santos, 2013). Through negotiations and pragmatic collaboration by the involved actors, the rivalry of competing institutional logics can be managed or made to 'work' without one logic eliminating the other and often without eroding the separate identities of key actors (Reay \& Hinings, 2009). In the healthcare field, several studies have identified two key, co-existing but polarized institutional logics, i.e., medical professionalism and managerialism or business-like healthcare (Reay \& Hinings, 2009; Scott et al., 2000; Yeow \& Faraj, 2011). The former focuses on clinician's responsibility for patients and quality of care, while the latter on cost-effectiveness of care and customer satisfaction and is often linked to the application of market mechanisms to healthcare. Currie and Guah (2007) propose that in UK healthcare, different logics co- 
exist and chart their eras of dominance, from (medical) professionalism, through managerialism to the application of market mechanisms, with other logics also present, e.g., business-focused logics of IT suppliers. Researchers have suggested that managerialist-driven applications of IS are resisted by the medical profession and often fail or are re-interpreted (Currie \& Guah, 2007; Doolin 1999). The notion of institutional logics allows us to link individual-level analysis of attitudes towards EHRs and responses to pressures to belief systems and practices at group and organizational levels.

Even though institutional theory has largely been used to study isomorphic behaviors of private corporations, researchers have argued that the theory is also appropriate for the study of public agencies, such as governments, in "national-level isomorphism" (Bromley \& Suárez, 2014; Luna-Reyes \& Gil-García, 2011). Indeed, a number of nation-states and national organizations have developed in structurally similar ways. Additionally, states also seek nationwide legitimacy, through use of national norms and principles, such as progress and justice. Thus, isomorphism can be seen in national structures and policies. Coercive, isomorphic and normative pressures are exerted in and between different types of organizations, both private and public. Therefore, we propose that institutional theory is appropriate for investigating implementation of national EHR programs, which involve both private and public sector stakeholders.

\subsection{Institutional Theory and HIT Implementation}

In the healthcare domain, institutional theory has been applied to explain the adoption and implementation of HIT. Survey-based studies have analyzed isomorphic pressures to adopt HIT on organizational stakeholders (e.g., Sherer et al., 2016; Fareed et al., 2015), or individual stakeholders, e.g., clinicians (Klöcker et al., 2014) and top management (Gopalakrishna-Remani et al., 2016). Klöcker et al. (2014) found that coerceive and mimetic pressures, but not normative pressures from the government or industry, had significant indirect effects on clinicians' decision to resist the introduction of the German Electronic Health Card (eGK). A study of EHR implementation in the US found that all three pressures, mediated by the contextual environment, influenced hospitals' adoption of EHR (Sherer et al., 2016). Fareed et al. (2015) examined the impact of factors that could make US hospitals comply with institutional pressures to implement EHR. Following Oliver (1991) they suggested that organizations may adopt different responses i.e., choose to yield to the institutional pressures, to cooperate, challenge, manipulate, or even avoid the institutional environment.

The findings of these studies are relevant to our research, as we are also interested in the ways that stakeholders (such as groups of clinicians) respond to pressures and how their responses may be environmentally mediated. Nevertheless, these studies differ significantly from ours. First, they utilize survey instruments, while our study uses a qualitative approach that provides more in-depth (though not as generalizable) insights. Second, they assess the impact of different kinds of institutional pressures on HIT (e.g., EHR or analytics systems) adoption by hospitals or individuals. In contrast, our paper examines the target national EHR implementations 
holistically by analyzing inter-related institutional pressures as exerted and experienced by key stakeholdes (both organizations and individuals involved) and how this could shape the outcomes.

There are also qualitative studies on the role of institutional pressures in national eHealth programs. Klöcker et al.'s (2014) literature review identified 33 case-based studies that used a macro prespective to examine countrywide eHealth programs, of which 7 studies explicitly examined the effects of institutional factors in those programs. Of these, 4 studies (Currie, 2012; Currie \& Guah, 2007; Jensen et al., 2009; Mekonnen \& Sahay, 2008) were about EHR implementation and, thus, particularly relevant to our work. Klöcker et al. (2014) did not find quantitative studies on this topic. A recent review by Sligo et al. (2017) did not reveal any additional articles on national eHealth programs from institutional perspective.

A number of claims emerge from these case studies. For example, Jensen et al. (2009) reported that while institutional pressures were normally exerted top-down e.g., from the institutional field onto organizations or individual actors, bottom-up processes may also influence HIT implementations. This view is re-enforced by Mekonnen and Sahay's (2008) research on how formal institutions e.g., policies, interact with various informal institutions e.g., the existing work practices, resource constraints, and staff capacity, in influencing HIT implementations. Currie and Guah (2007) examined the institutional logics and governance structures in England's NHS organizations. They noted that the growing fragmentation of the healthcare field and conflicting institutional logics made it difficult to attain agreement on the aims and objectives of NPfIT. In another study, Currie (2012) illustrated how coercive pressures i.e., government policy, to impose a standardized, shared EHR and to change working practices in England's NHS, were thwarted by isomorphic structures, including established clinical routines, norms and behaviors of clinicians. Specifically, normative pressures arising from professionalism (doctors belonging to professional bodies) played an important role in the resistance to EHR in the UK context (Currie, 2012).

In addition to these studies, Azad and King (2012) described how clinicians resorted to workarounds to cope with top-down institutional pressures, such as policies and standards and computer systems that embedded them, and bottom-up pressures of day-to-day work material constraints that made adherence to those policies difficult in practice. In doing so, enacted practices (actual system use) became disconnected from the formal policy (design use). While some studies take institutions and institutional fields as their level of analysis (e.g., Scott et al., 2000) others adopt a 'micro' focus on actions and practices of actors performing 'institutional work' (Azad \& King, 2012; Reay \& Hinings, 2009; Yeow \& Faraj, 2011). Currie and Guah (2007) advocate a multi-level analysis, reflecting on how societal, inter-organisational, and individual (agency) factors influence the institutional environment of healthcare. Progressing the above studies, our research links different levels of analysis and considers institutional conditions (such as the structure of the healthcare field, existing IT infrastructures and project organization), and dynamics of institutional 
pressures as exerted through and experienced by different stakeholders in national EHR implementations in two different countries.

\subsection{Conceptualizing Stakeholders in EHR Implementation}

Key to answering our research questions is the identification of stakeholders and understanding how they dynamically exert or experience institutional pressures and hence influence nationwide EHR implementations. Drawing on stakeholder theory (Freeman, 2010; Mitchell et al., 1997) and on information systems literature theorizing of IS stakeholders (Boonstra and de Vries, 2008; Lamb, 2006; Pouloudi et al., 2016) we conceptualize stakeholders in our study as institutional actors (e.g., individuals, groups, and organizations) that affect or are affected by EHR deployment and use, and are conditioned by organizational and national contexts. Thus, our concept of stakeholder is much broader than 'IT user' and includes those stakeholders which might directly or indirectly influence policy and strategies of EHR implementation. Stakeholder numbers and types are both context and time dependent. Prior research on IT-enabled healthcare integration has identified various stakeholders, including patients, physicians, IT suppliers and government bodies (Evans et al., 2013; McLeod Jr \& Clark, 2009) as well as consultants, pressure and professional groups and media (Pouloudi et al., 2016).

Stakeholders may have multiple roles, and their perceptions and values may change over time. Their actions are often intertwined and influence each other dynamically (e.g., in the way they respond to institutional pressures). A stakeholder attribute, defined as a relational attribute, i.e. depending on which stakeholder relations we study at what point of time, is useful to understanding the interaction between different entities. Particularly, stakeholder attributes are investigated to understand how a stakeholder can influence an organization, a project, or any other stakeholders and how it can be influenced. For this purpose, Mitchell et al. (1997) suggest focusing on stakeholders' attributes of power, legitimacy and urgency. Specifically, they define power as the extent to which an actor can impose its will in a relationship; legitimacy is the generalized perception that the actions of the actor are accepted and expected within a socially constructed system of norms, values, beliefs, and definitions; and urgency refers to whether stakeholder's claims call for immediate attention of the organization based on time sensitivity. Among these, power and legitimacy are suggested as core attributes for defining dominant stakeholders (Agle et al., 1999; Rawlins, 2006). The IS literature illustrates how stakeholders' power, interests and values, and in particular work ethos, influence their perceptions of HIT and their ability to shape related policy and strategies before and during implementation (Petrakaki \& Klecun, 2015; Pouloudi, 2016). Also, it discusses how they apply discretion when using (or refusing to use) such systems (Azad \& King 2012; Petrakaki et al., 2016).

We conceptualize stakeholders' power as relational, i.e., in relation to their ability to influence other actors, as dynamic, having diverse forms and locations, and as being dependent on structural relations (Foucault, 1979). Although we eschew an essentialist perspective of power we do not subscribe to the view that power resides between actors and cannot be attributed to any particular actor. Thus, we 
study how different stakeholders may exercise power (through exerting different pressures) drawing on resources they command and legitimacy they claim. It is only in this dynamic and relational sense that we refer to power as an 'attribute' of a stakeholder. But power itself is not sufficient to understand actors' influence, e.g., individuals or organizations with little formal power may draw influence from their legitimacy. Whilst urgency is not explicitly discussed in organization theories, it is implicitly included. Indeed, the attention-getting capacity of the urgent claim is suggested to be important in the relationship between a manager and other stakeholders or between other stakeholders. For example, in the English case study, perceived urgency of claims made by different healthcare organizations influenced how they were dealt with by the central coordinating agency.

\subsection{An Integrative Framework}

To progress current literature in stakeholder and institutional research on healthcare integration, we apply institutional and stakeholder theories as our theoretical lenses to provide insights into the mutual influences of multiple institutional actors over time in the nationwide EHR implementations. Particularly, the concepts of stakeholder attributes allow us to describe the salience of stakeholders, while institutional theory helps identify the dynamic pressures through which these attributes support stakeholders' mutual influence. Figure 1 shows our theoretical framework integrating relevant concepts from institutional theory and stakeholder identification. In the framework, stakeholder attributes are closely related to the institutional pressures they exert or experience. For example, the power attribute of stakeholder salience is related to the coercive pressures the stakeholder can exert on its external environment, while legitimacy can explain a stakeholder's ability to employ normative pressures. Additionally, institutional theory, which explicates the evolution over time of the institutional environment, provides insights into understanding how this may influence stakeholders' interactions. Different institutional pressures can be inter-related and influence each other to drive the changes in the institutional environment. By weaving these theoretical lenses together, we aim to develop a richer understanding of complex, multi-stakeholder and long-term HIT implementations, in this case for national EHR programs.

We combine the concepts of institutional pressures with the notion of institutional logics, such as professionalism, managerialism and market logics, in order to gain a better understanding of why certain innovations (such as EHR) become institutionalized (or not). We employ Townley's (1997) position that institutional logic is an important factor influencing responses to isomorphic pressures. We suggest that external processes of deinstitutionalization and institutionalization of innovations have to be understood together with the internal dynamics of interpretation, adoption, and rejection of the innovation by the individual organization. To examine those we focus on stakeholders' agency, i.e. their capacity to interpret, manipulate and resist isomorphic pressures and reflect on and influence institutional logics. 


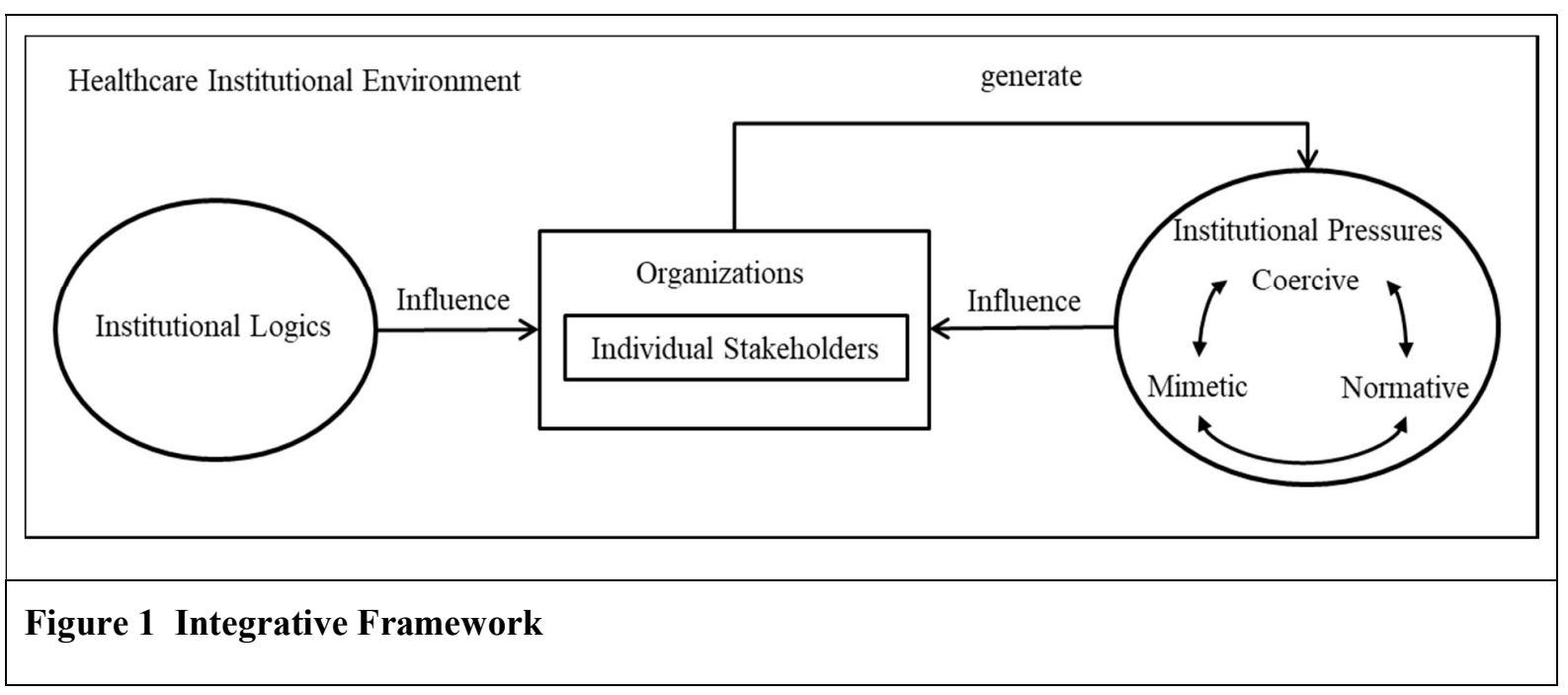

\section{METHODOLOGY}

\subsection{Methodological Approach}

Healthcare integration through national EHR programs represents a complex real-life process. We adopted an interpretative case study approach as this supports the description of such social phenomena in context (Walsham 1993). This allowed our reflection on the nuanced institutional processes at play, and stakeholders' perspectives and saliences. Our analysis was informed by our theoretical framework, which was instantiated through our case analysis. To address our research questions we focused on two examples of integration programs, Singapore's National Electronic Health Records (NEHR) program, and the English NHS' Care Records Service (NCRS) as part of the NPfIT program.

We are interested in those two countries because they adopted broadly similar implementation models of EHR (top down, standardized solutions) but experienced significantly different results, Singapore's program being viewed as broadly successful, England's as a program that faced significant challenges (Currie, 2013; Sheikh et al., 2011; Syal, 2013). The two countries differ widely in their political and institutional conditions (i.e. size and complexity of the field, including the quantity, heterogeneity and autonomy of stakeholders), and existing IT infrastructures, whilst exhibiting both similarities and differences in their healthcare model (e.g. private/public split) and governing structures. The examples of the two countries allow us to analyze how institutional pressures to adopt EHR dynamically play out (are exercised and responded to) under different institutional conditions.

\subsection{Data Collection}

In order to understand the EHR implementation phenomenon and to instantiate our framework, we used primary and secondary data (Noor, 2008) for both nations. Primary data was obtained through interviews with key personnel from organizations participating in the EHR implementations, and secondary data from public 
documents, such as policy statements, reports, presentations, and news articles.

For the Singapore case, our analysis was based on primary data collected during 2013-2015 and from secondary data sources produced during 2006-2015. Our primary data consisted of interviews with key personnel at the Ministry of Health (MOH), Ministry of Health Holdings (MOHH), Agency of Integrated Care (AIC), Integrated Health Information Systems (IHIS) and Acute Public Hospitals (APH), as well as doctors at general practitioner (GP) clinics and polyclinics. The sample interviewed consisted of clinicians (20\%); managers and administrative staff (40\%), IT representatives from public agencies responsible for the implementation of NEHR (20\%), and representatives from private service providers (20\%). Secondary data was taken from the webpages, presentations, policies and reports of public agencies (e.g., $\mathrm{MOH}, \mathrm{MOHH}$ ), IT vendors' documents, and online news. We conducted 15 semi-structured interviews (face-to-face or by email) and analyzed 74 documents from public agencies and other stakeholders, news articles and webpages (see Appendix A for details).

For the English case ${ }^{2}$, we reviewed policy and strategy papers spanning the period 1998-2016. For the NPfIT initiative we drew on data from a large evaluation of NCRS adoption conducted between 2009 and 2011 (see Appendix C for details). Here, we directly reference the relevant sub-set of the interviews (33 in total) conducted by a research team of which one author was a member. This sub-set consisted of clinicians, including physicians, nurses and allied health professionals (48\%); managers and administrative staff (6\%); IT managers and specialists (27\%); government agency representatives (from the Strategic Health Authority) (6\%); EHR providers from private sector $(12 \%)$.

In Singapore, the preliminary research framework was developed based on stakeholder and institutional theories, which guided the subsequent data collection. For the English case, data collection was guided by a socio-technical perspective that emphasized concepts of power, identity, stakeholder institutionalization, as well as healthcare transformation in relation to IT policy, strategies, design, implementation and use.

\subsection{Data Analysis}

Our cases, Singapore's NEHR and England's NCRS were analyzed separately using the methods described below, following which the findings were compared across the two cases. We combined top-down, thematic coding guided by concepts in our framework of Figure 1 and bottom-up, inductive coding that allowed themes to emerge from the data. Examples of thematic coding included specific mechanisms of exerting isomorphic and market pressures (e.g., regulations and incentives) that influenced EHR implementation in each country, institutional logics present in the organizations involved, stakeholders' claims to legitimacy, and their ability to exercise power. We then searched for relationships in the data (such as dependencies between different stakeholders and groups, and sequences/ links between pressures and counter-pressures),

\footnotetext{
${ }^{2}$ To make our scope more tractable we focused on EHR implementation in England and not in the entire UK, as each nation in the UK pursued different policy. England is the largest constituent of the UK.
} 
and conducted cross-checking of tentative findings within each case (country) and between the countries (Miles \& Huberman, 1994). This was an iterative process as advocated in the literature (Klein \& Myers, 1999). Whilst comparing the data from both countries we focused on stakeholders and groups, institutional pressures, logics and dynamics. We also took into consideration institutional conditions, such as national context (size, area, and political condition), healthcare provision model, existing IT infrastructure, as well as project organization, including funding, delivery of systems and outcomes of the program in terms of adoption rates (see Appendix E and Tables 1 and 2 for detailed comparisons).

Our aim was to "delineate the deep structure and then to integrate the data" (Miles \& Huberman, 1994, p.91), as per our explanatory framework, i.e. to produce plausible explanations of how institutional pressures work in different contexts and in relation to particular HIT implementation models. We do not claim, however, to prove causal links between discrete variables, and acknowledge that the generalizations we do suggest should not be seen as universal laws but rather as insights derived from particular settings that may be valuable in other contexts as well (Walsham, 1995). The findings from each country are discussed next, followed by a cross-country comparison.

\section{FINDINGS FROM SINGAPORE}

To address our research questions within the Singapore context, we describe the results of our analysis of primary (interviews) and secondary data sources (e.g., public agency reports, news). For details of the data for this case, refer to Appendices A and B. In this section, we begin with an introduction to Singapore's healthcare system and then discuss the origins, goals, and institutional processes in relation to our integrative framework for NEHR implementation.

\subsection{Overview of Healthcare in Singapore}

Singapore is a developed Asian city state with a population of 5.61 million (DOS, 2016) and has one of the most efficient healthcare systems, in terms of life expectancy vs. per-capita healthcare spending (Du \& Lu, 2016). In Singapore, the Ministry of Health (MOH) is responsible for devising healthcare policies that aim to provide accessible, affordable, quality health services. Ministry of Health Holdings (MOHH) is the holding company for Singapore's public health entities (clusters) and assets. MOHH is also the strategic partner of $\mathrm{MOH}$ in implementing healthcare policy across public healthcare organizations. Primary healthcare in Singapore is mainly (i.e., 80\%) delivered through private general practitioners (GPs), while $20 \%$ is provided through government polyclinics ${ }^{3}$. On the other hand, tertiary hospital services are mainly $(80 \%)$ provided by public hospitals, with the remaining by private hospitals. For patients who require continuing care after discharge from the hospitals, there are also Intermediate and Long Term Care (ILTC) organizations, such as community hospitals (CHs) and nursing homes (NHs).

\footnotetext{
${ }^{3}$ https://www.moh.gov.sg/content/moh_web/home/statistics/healthcare_institutionstatistics.html
} 
In 1985, to increase healthcare efficiency, Singapore undertook a program of healthcare privatization. This restructuring policy, however, led to "counter-productive" competition, that increased costs, inefficiencies and produced data-silos (Okma et al., 2010). To shift competition from between individual institutions to between integrated networks, public healthcare was reorganized into two clusters in 2000 (Shum \& Lee, 2014), i.e., the National Healthcare Group (NHG) and SingHealth. During this process, most hospitals (more than $80 \%$ hospital beds) were changed to public ownership. After the transformation, public hospitals could enjoy operational autonomy and still participate in market competition, but their strategies were under government control (Ramesh \& Bali, 2018). However, to support its integrated healthcare vision, which aims to facilitate the continuity of care for patients, Singapore further reorganized the two clusters into a Regional Healthcare Services (RHS) framework in 2010 (Shum \& Lee, 2014). The framework encompasses six clusters spread across the island ("regions"), each offering comprehensive healthcare (from primary to long term care) ${ }^{4}$. Each region is anchored by an acute public hospital (APH) that works closely with other healthcare organizations (i.e., community hospitals, nursing homes, GP clinics, and polyclinics) in the region, government agencies (e.g., $\mathrm{MOH}, \mathrm{MOHH}, \mathrm{IHIS}, \mathrm{AIC}$ ), and volunteers, with participants from both public and private sectors. The RHS model intended that patients need not travel outside their region to seek medical services. To support this integrated care vision, staff members from IT departments of all healthcare clusters were brought together to form the Integrated Healthcare Information Systems (IHIS) body in 2008. IHIS aims to create a strengthened and consolidated IT workforce to empower Regional Healthcare Services ${ }^{5}$. In addition, the Agency for Integrated Care (AIC) was formed in 2009 to link primary care and Intermediate and Long Term Care through each cluster's Acute Public Hospital. ${ }^{6}$ AIC's aim was to link primary, secondary, and tertiary care for each patient. Critical to Singapore's integrated care vision is the National Electronic Health Record (NEHR), which origins, goals and adoption we describe in the following section.

\subsection{Origins and Goals of NEHR}

Two clusters in the public healthcare division, i.e., NHG and SingHealth, were created in 2000 characterized by horizontal and vertical integration (Shum \& Lee, 2014), bringing together assets across the healthcare spectrum ranging from polyclinics in primary care, to the acute hospitals and specialist centers of secondary and tertiary care (Mok \& Forrest, 2008). As a result, each cluster developed their own IT systems (Okma et al., 2010; Sinha et al., 2013). The NHG cluster's electronic medical record ( $\mathrm{EMR}^{7}$ ) system called CPSS (Computerized Patient Support System) was self-built by IHIS, while the SingHealth cluster's system was a commercial product (Eclipsys). This led to "fragmented and relatively uncoordinated healthcare services" (IDA, 2006) across the

\footnotetext{
${ }^{4}$ Subsequent to our study, the RHS framework had further changes. As announced in Jan 2017, Singapore's public healthcare system would be reorganized from 6 clusters to 3 integrated clusters. The reorganization has been completed in early 2018 .

${ }^{5} \mathrm{https} / / /$ www.ihis.com.sg/About_IHiS/Pages/milestones.aspx

${ }^{6} \mathrm{https}: / /$ www.aic.sg/about-us/more-about-aic

${ }^{7}$ EMR refers to the digital version of erstwhile patient paper records in a single healthcare organization, while EHR are designed to share patient records beyond single health organizations that collect and compile patient information.
} 
two clusters within Singapore's healthcare systems. Moreover, since the two clusters did not include healthcare services from private healthcare providers, who are responsible for $80 \%$ of Singapore's primary healthcare services $^{8}$, achieving continuity of patient care was challenging (Shum \& Lee, 2014). Furthermore, at that time, primary care providers, such as GPs, did not possess EHRs or EMRs.

Through reviewing the clustering experience, $\mathrm{MOH}$ progressively refined the healthcare delivery model to promote integrated healthcare in Singapore. This led to the reorganization of clusters and the establishment of the Regional Health Services (RHS) framework and Regional Health Systems, with the aim to facilitate close partnerships and collaboration beyond the public health institutions, and include private healthcare providers and voluntary welfare organizations into the efforts in patient-level care (Shum \& Lee, 2014). Prior to NEHR, the Electronic Medical Records Exchange (EMRX) was implemented in 2004 for secure cross-cluster exchange of patient information. However, EMRX had a major drawback, as it was essentially a document-level exchange, with no standardized or structured data. Seamless sharing of data beyond documents was impossible, e.g., diagnostic images, including X-rays, could not be exchanged over EMRX ${ }^{9}$.

Thus, to support seamless data transmission across care organizations under a "One Patient - One Record" vision NEHR's objective was to create one care record for each patient over time by consolidating all relevant healthcare information through secure inter-organization information sharing (Kwee, 2009). NEHR was envisaged as a single, provider agnostic EHR system with a central database. It was intended for use by all public and private healthcare providers (Muttitt et al., 2012).

The NEHR project officially received funding in 2009 (Hodge, 2011), although preliminary explorations began in 2008 (Muttitt, 2008). For the NEHR design and implementation, MOH instructed MOHH to carry out the NEHR project and deliver the systems on its behalf. IHIS worked with the IT teams from MOHH in the integration of different IT systems and NEHR. Furthermore, commercial solution providers were introduced through contracts, i.e., an Accenture-led consortium was responsible for developing the NEHR systems and infrastructure, and also with integrating legacy systems into NEHR.

\subsection{Institutional Logics and Processes}

The stakeholders in the NEHR project ranged from organizations to individuals. Specifically, at the organization level, there were acute public hospitals (APHs), which were at the center of each RHS cluster; other healthcare providers in each cluster, i.e., community hospitals (CHs), polyclinics, GP clinics, and nursing homes $(\mathrm{NH})$; the public sector organizations guiding or implementing NEHR program, i.e., Ministry of Health Holdings (MOHH), Ministry of Health (MOH) and Integrated Health Information Systems (IHIS); and a commercial NEHR consortium of vendors led by Accenture. Individual stakeholders included Chief medical information officers

\footnotetext{
${ }^{8}$ https://www.moh.gov.sg/content/moh_web/home/statistics/healthcare institutionstatistics.html

9 https://www.moh.gov.sg/content/moh_web/home/pressRoom/Parliamentary_QA/2010/Update_on_the_National_Electronic_He alth_Records_System.html
} 
(CMIO), healthcare professionals (e.g., doctors), and administrators. Figure 2 depicts the organizational stakeholders and the institutional processes of NEHR implementation, discussed in detail next (all evidence summarized in Appendix B).

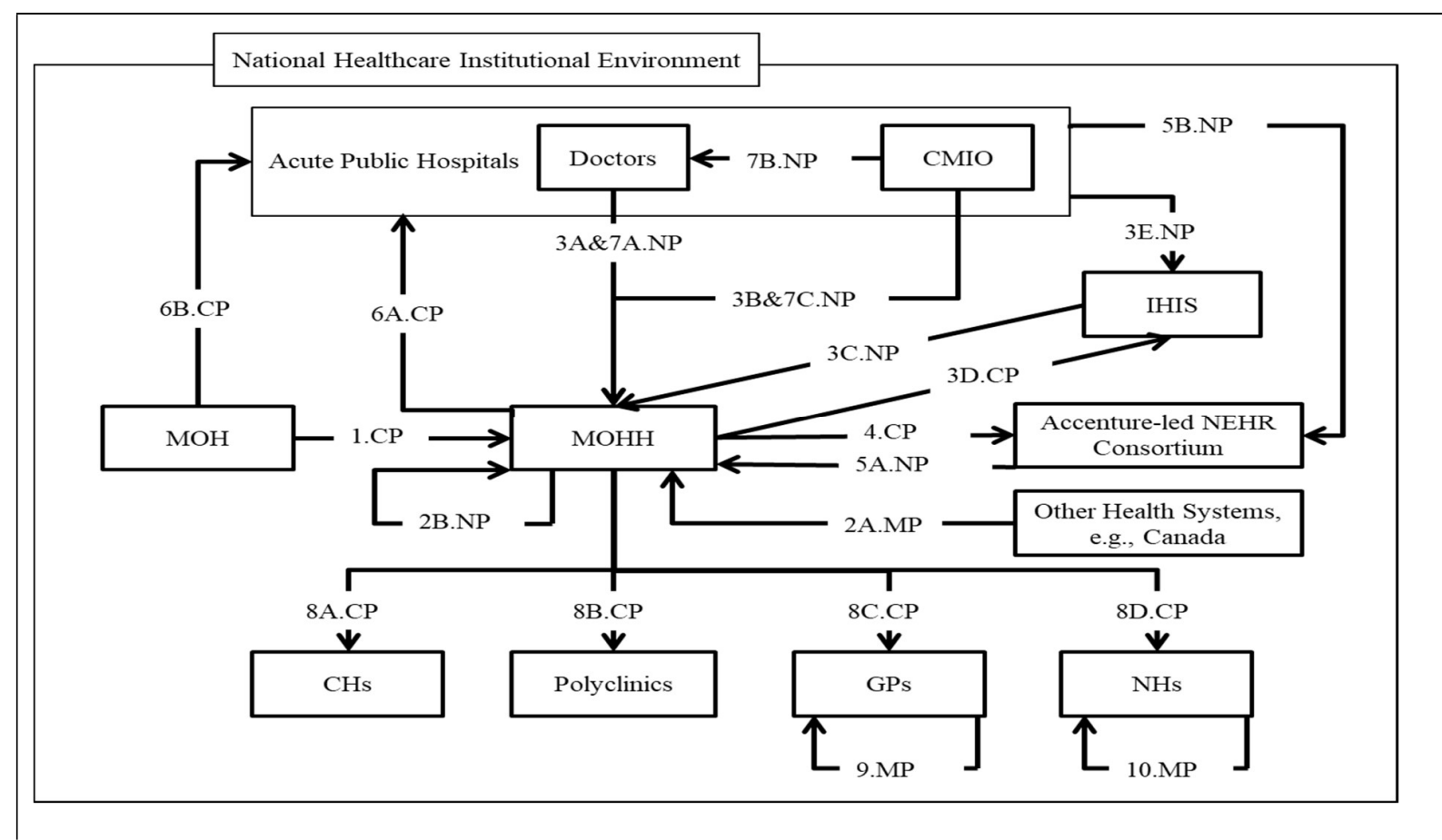

\section{Figure 2 The Institutional Processes of NEHR}

Note: $\mathrm{NP}=$ normative pressure, $\mathrm{CP}=$ coercive pressure, $\mathrm{MP}=$ mimetic pressure

Numbers next to these letters (e.g., 1.NP) are indicative of the chronological order of pressures observed, but it should be noted that many pressures were continuous or iterative. Same numbers (e.g., 2A and 2B) indicate concurrence.

$\mathrm{APH}=$ acute public hospital, $\mathrm{CH}=$ community hospital, $\mathrm{CMIO}=$ chief medical information officer, $\mathrm{GP}=$ general practitioner, IHIS=Integrated Health Information Systems, $\mathrm{MOHH}=$ Ministry of Health Holdings, $\mathrm{MOH}=$ Ministry of Health, $\mathrm{NH}=$ nursing home

Having greater power than $\mathrm{MOHH}, \mathrm{MOH}$ sought to use its authority and resources to assign $\mathrm{MOHH}$ (coercive pressure 1. $\boldsymbol{C P}$ ) the task of carrying out the NEHR project on its behalf. In the process, power transference took place and MOHH drove the NEHR project. A MOHH senior manager revealed that NEHR was "planned, designed, and managed, top-down from here (MOHH)". Moreover, MOHH was able to draw on its ownership of all public healthcare assets, including public healthcare providers (e.g., APHs), manpower and funding to influence the implementation of NEHR project. Thus, it now had power and legitimacy over other stakeholders.

When designing and implementing the NEHR project, MOHH was influenced by mimetic pressure $(2 A$. MP) based on the similarities of Singapore's MOHH and Canada's Health Infoway organization in governing EHR projects (Muttitt, 2008). This was facilitated by bringing in overseas consultants (e.g., Dr. Sarah Muttitt, 
from Canada Health Infoway was recruited as MOHH CIO in 2007) into the MOHH NEHR leadership team. MOHH's Information System Division adapted the proposed NEHR solution based on Canada Infoway's EHR experiences. These consultants worked as the employees of MOHH and exerted normative influences (2B. $\boldsymbol{N P}$ ) based on their past EHR experiences from other countries and professional bodies within MOHH. Coupled with the above mimetic pressure (2A. MP), this normative pressure further aided the "travel of ideas" as experiences from Canada's Infoway EHR were incorporated into the NEHR design.

Other normative pressures $(\mathbf{B A}$. NP) on MOHH during the design of NEHR stemmed from the formation of a steering committee (Clinical Advisory Group) comprising of 5 different taskforces (Data stewardship, Summary care record, Computerized provider order entry \& medication management, Secondary data-use, Diagnostics) that looked after various NEHR clinical informatics aspects alongside the governance aspects (Brooks, 2010). This allowed for stakeholders comprising of different institutional logics to be represented, ranging from managers encompassing market or managerialism logics to doctors abiding by their professionalism. The steering committee (with 5 taskforces) structure was an attempt to manage the competing institutional logics, so as to ensure that the interests of all stakeholders were balanced and represented. Additionally, the IT Manager of one of the APHs noted that their Chief Medical Information Officer (CMIO) played a "pivotal role by providing critical clinical directions and inputs". This reflects the CMIOs' normative influence (3B. NP) which was integral throughout the process because of their ability to relate IT with their professional interests (as doctors). This allowed for accurate requirements to be gathered so that NEHR remained clinically relevant for doctors. Another normative pressure (3C. NP) came from IHIS that provided "knowledge about the ground operations for the NEHR team" [IHIS Senior Manager 2] to MOHH.

As a subsidiary of MOHH, the Integrated Health Information Systems (IHIS) agency also experienced coercive pressure (3D.CP) from MOHH to integrate different systems with NEHR. For example, it worked with MOHH to standardize data from the different EMR systems of SingHealth and National Healthcare Group for integration with NEHR. IHIS standardized, extracted, transformed, loaded and did "a lot of mapping" of the relevant data. Furthermore, originally formed by the IT staff members from healthcare clusters, IHIS employees worked closely with the healthcare workers in the hospitals, IHIS was influenced by the normative pressures (3E.NP) from doctors and took consideration of their professional needs.

In addition to IHIS, the Accenture-led NEHR consortium was an important system integrator. It was stated they also "do the infrastructure and development of NEHR system" [IHIS senior manager]. MOHH exerted coercive pressure (4.CP) on this consortium through awarding contracts. The consortium then worked with MOHH during the design of NEHR through exerting normative pressure (5A.NP). In order to better understand their professional needs, Accenture engaged doctors from hospitals and analyzed their requirements, during which time the hospitals exerted normative pressures on the consortium (5B.NP). 
To create exemplar organizations of NEHR implementation in the healthcare system, and populate the initial database for NEHR, MOHH first delivered NEHR to the Acute Public Hospitals (APHs) in the two clusters through application of coercive pressure (6A. $\boldsymbol{C P}$ ). MOHH attempted to co-opt the public APHs first, rather than private healthcare providers for two reasons. First, MOHH held the public ownership of APHs and had the power to directly control the behavior of APHs. It was noted by the senior manager, "when the instruction or the policy directions have been made at the government level... you're (public healthcare institutions) with $i t$ '. The other reason is that APHs held high legitimacy in NEHR effort by serving as anchors for each RHS and contributing more than $90 \%$ of the population's healthcare data [MOHH senior clinician]. The coercive pressure (6A. $\boldsymbol{C P}$ ) was further facilitated by the resources of MOHH. A MOHH IT manager mentioned, "NEHR is ... free to the provider... and funded by a capital grant from the government". At the same time, to ensure that there were appropriate mechanisms governing the security and jurisdictions of the shared data, $\mathrm{MOH}$ exerted coercive pressure (6B. $\boldsymbol{C P}$ ) over APHs through enacting policies, such as the Data Protection Policy (EHA, 2014; SingHealth, 2014).

In turn, MOHH was subject to normative pressures (7A.NP) from hospital doctors in two ways. First, feedback on NEHR was sought from doctors within APHs. An APH senior clinician explained, "every time they $(\mathrm{MOHH}$ ) launch one version they make us (doctors) test it". Doctors gave feedback to MOHH on existing processes such as the NEHR registration method. As noted by an APH senior clinician, "a lot of people didn't bother to register... we basically told them (MOHH) no one was going to use it (NEHR)". Second, when the EMRX system was to be deprecated in order to make way for NEHR, doctors resisted such a change, telling MOHH, “you cannot shutdown the EMRX” [MOHH Senior Manager] because they had become well acquainted with the system.

Throughout this process, APHs' Chief Medical Information Officers (CMIOs) played an essential role in increasing NEHR adoption and improving its design to meet doctors' requirements. They exerted normative pressures both within (7C.NP) and outside (7B.NP) their APH. Internally, within hospitals, because of their position, an IHIS Senior Manager noted that CMIOs had the "authority to convince their fellow colleagues". As a result, they were appointed as "change champions" [APH Senior Clinician] to increase NEHR adoption amongst fellow doctors through normative pressure (7C.NP). Externally to MOHH, an IHIS senior manager noted, "they (CMIOs) are very involved ... right down to how things are displayed on screens" (7B.NP). Aiming to incorporate medical professionalism into managerialism, CMIOs helped alleviate the conflicts between the institutional logics of APHs and that of MOHH managers. Specifically, the CMIOs and doctors in the APHs mainly subscribed to professionalism logics, while MOHH managers followed mainly managerialism or market logics.

After achieving success with implementing NEHR among APHs, from 2012, MOHH began to involve the rest of the public and private healthcare organizations. For example, since community hospitals (CHs) and 
polyclinics wee under the purview of APHs' healthcare systems, MOHH directly exerted coercive pressures $(\mathbf{8 A} \boldsymbol{\&} \mathbf{B} \boldsymbol{B} . \boldsymbol{C P})$ on them. Specifically, CHs adopted the same system with their own cluster APHs while all the polyclinics adopted the same system. Particularly, under the RHS framework, CHs needed to be tightly integrated with APHs in order to provide step-down care for patients who have just been discharged from APHs. This ensured continuity of care and eased APH's high bed-occupancy rate, reflecting CHs' urgency and legitimacy in NEHR access.

On the other hand, as involvement of private healthcare organizations (e.g., GP clinics and some NHs) in NEHR was not under MOHH's direct control, a "soft approach" was applied as mentioned by a MOHH Senior Clinician through its leverage of subsidies, incentives, and IT enablement schemes. First, MOHH offset NEHR costs to alleviate the concerns from those providers, who espoused the market logic and "were very worried about (NEHR) costs". As most of them lacked IT capability and legacy systems, MOHH took the opportunity to pursue concurrent IT enablement programs for GP clinics (i.e., CLEO ${ }^{10}$ - Clinic EMR and Operation system) and NHs (i.e., NHELP ${ }^{11}$ - Nursing Home IT Enablement Program). Particularly, MOHH sought to leverage funding programs to exert coercive pressure on GP clinics (8C.CP) and NHs (8D.CP), and thereby promoted the adoption of the IT-enabled programs for NEHR access indirectly.

For example, as $80 \%$ of Singapore's population uses private GP clinics for primary care ${ }^{12}$ and some of them are eligible for government healthcare funding schemes, GP clinics were enticed to implement a capable IT setup (e.g., through the CLEO program) and submit claims via accessing a (web) portal for them to log into to get information from the NEHR. As a MOHH senior manager rationalized, "sooner or later... if you want these patients, then you have to do this (be IT-enabled and use NEHR)". Rapid adoption of NEHR by GPs can also be explained by the mimetic pressures (9.MP) from other GP clinics in response to uncertainties stemming from a changing model of care and the formation of RHS. To create momentum, a MOHH senior manager commented that a pioneer group of GPs was chosen as a model to other GPs. These pioneers were described as "very progressive people who were ready to go", e.g., those who embodied professionalism logic (as observed by a GP, "from my perspective, patient care comes first, and we aim to do that and then if they can pay us, good"). Similarly, in order to entice Nursing Homes (NHs) to implement the NHELP, MOHH offered "NHELP free to nursing homes for three years (Lee, 2014). They also mentioned attempts at creating mimetic pressures (10.MP) on nursing homes. An APH senior manager noted that in order to get more nursing homes on board NHELP, they planned to "bring along the nursing homes who have already adopted NEHR to come and share with them (potential NEHR adoption nursing homes) the usefulness... easier to get one of the champion to sell".

By June 2013, NEHR has been implemented in all public hospitals, all polyclinics, as well as some

\footnotetext{
${ }^{10}$ https://www.moh.gov.sg/content/moh_web/home/pressRoom/speeches_d/2011/closing_address_bymsyongying-ipermanentsecretaryhealthatthenatio.html

${ }^{11} \mathrm{https}$ ://www.ihis.com.sg/Project_Showcase/Healthcare_Systems/Pages/NHELP.aspx

${ }^{12}$ https://www.moh.gov.sg/content/moh_web/home/statistics/healthcare institutionstatistics.html
} 
Community Hospitals (CHs), NHs, and GP clinics - as per the targets of its first phase. Since then MOH has actively encouraged private healthcare providers not yet on board to adopt NEHR ${ }^{13}$. As Singapore's healthcare system adapts to fulfill changing health needs, NEHR is also evolving. MOH has developed a Health IT Master Plan (HITMAP) $)^{14}$, with relevant public and private sector stakeholders to guide IT-enabled healthcare integration efforts forward, including NEHR.

\section{FINDINGS FROM ENGLAND}

To address our research questions for the English context, we describe results from our analysis of primary and secondary data sources (Appendices C \& D provide details of the data for this case). We begin this section with an introduction to England's healthcare system and then discuss the origins, goals, and institutional processes in relation to our integrative framework for the National Programme for IT (NPfIT) National Care Records Service (NCRS).

\subsection{Overview of Healthcare in England}

Public health provision is managed by National Health Services for each of the UK's constituent nations. Each service adheres to the principle of a tax-funded socialized healthcare system providing most services free at the point of delivery. The National Health Service (NHS) in England, hereafter simply the NHS, procured healthcare services for 53.1 million citizens in 2011 (Office for National Statistics, 2011). Over the last 70 years, the NHS has seen considerable institutional change. Although the Department of Health (DH) continued to be responsible for the funding, direction and organizational transformation of health and social care, the underlying structure has changed. When NPflT launched in 2002, there was political consensus around separating the functions of healthcare commissioning and healthcare provision (NHS Community \& Care Act (1990)). The NHS at this time was divided into regional Primary Care Trusts $(\mathrm{PCTs})^{15}$, responsible for commissioning services from acute, mental health, and community health trusts (DH, 1997). In 2003, these were joined by Foundation Trusts (FTs), semi-autonomous healthcare providers. Over the period of NPfIT, oversight of NHS trust performance was managed by regional Strategic Health Authorities (SHAs), which would also take responsibility for promoting health informatics use (Talbot-Smith \& Pollock, 2006).

\subsection{Origins and Goals of the NPfIT}

Since 1998, English healthcare policy has promoted EHRs as a support for integrated care by providing access to up to date patient health information from healthcare providers (Klecun, 2016). This vision has historically been hampered by the proliferation of incompatible software and a lack of agreed standards for data sharing. In

\footnotetext{
${ }^{13}$ https://www.moh.gov.sg/content/moh_web/home/pressRoom/pressRoomItemRelease/2013/speech-by-minister-for-health--mrgan-kim-yong--at-the-opening-c.html

14 https://www.moh.gov.sg/content/dam/moh_web/healthscope/archive/2012/MOH\%20Healthscope_July-August\%202012\%20Issue.pdf

${ }^{15}$ The NHS organizations such as primary care practices, hospitals, mental health and ambulance services are grouped into trusts.
} 
the early 2000s, technological silos predominated in the NHS at inter- and intra-organizational levels, the majority of information stored on paper (Brennan, 2005). Primary care was the only sector where computerization efforts proved successful. Coercive and normative pressures, including subsidies for IT adoption and contractual reporting requirements, led to high rates of GP practice computerization (Benson, 2002). However, these systems were stand alone. The influential Wanless report (2002) on the future of the NHS recognized these challenges and called for a doubling of IT investment.

Against this background, England's NPfIT launched in 2002. NPfIT was built on a strictly enforced top-down large-scale implementation model following an ethos of 'ruthless standardization' (DH, 2002). A new National Care Records Service (NCRS) was proposed as part of NPfIT. This would provide a centrally-shared patient record expected to improve diagnosis and safety through, for example, a shared record of patient allergies, inter-professional collaboration, and more recently, data-sharing for research. NCRS comprised two projects, a nationally accessible summary care record (SCR) of emergency information for each citizen, and locally-stored detailed care records, the Care Records Service (CRS) that could potentially be shared between different providers. Record sharing was supported through a new National Network for the NHS (N3) and a set of centralized services (the Spine). These services also enabled additional applications, such as electronic referrals and prescriptions, and digital image transmission; services built to standards that enabled data sharing across the NHS.

NPfIT goals were isomorphic not only aiming to implement standardized software (offered without charge to NHS contractors and providers), but also to standardize clinical practice through embedding in the software 'best practices', such as clinical pathways and protocols, and supporting the use of standardized clinical codes. This proved problematic from the start, given the NHS is both a highly diverse environment with varied local service providers and a strongly institutionalised one, “... there is nobody at the top saying you will do this like this, everybody wants to do it their own way...we're basically made up of hundreds and hundreds of organisations that hate each other and will not talk to each other, will not play ball together [IT Manager, Site 4]. The independent origins of many NHS organizations led to a "level of variability across the trust [that is] staggering. I was amazed how different everything is, everything is different, hospital to hospital, right down to simple things like the color of labels on the blood bottles for the different sciences [LSP Manager 1]. This level of heterogeneity is also present in the IT systems, where "each hospital [...] is a completely discrete island of mostly paper but some electronic data". [LSP Manager 2]

\subsection{Institutional Logics and Processes}

From government agencies, to healthcare professionals, to the general public, many groups had a 'stake' in NPfIT. Its governance included oversight from a ministerial taskforce and a Department of Health (DH) Director, who reported to the Parliamentary Under-Secretary of State for Health, the NHS Chief Executive, and the Permanent Secretary at DH. The Program Director had day-to-day responsibility for running the program 
and managing funds. The NHS Information Authority (IA) was initially involved in program delivery until 2005 when DH disbanded it and set up Connecting for Health $(\mathrm{CfH})$. CfH took charge of development and delivery of NPfIT, including setting the new system specifications. Additionally, SHAs took responsibility for promoting HIT, including NPfIT solutions.

The stakeholders in NCRS implementation also included various healthcare providers, from primary (GPs), secondary and tertiary healthcare organizations. Within these organizations, there existed several stakeholder groups. Broadly, these included hospital management, clinical and other groups. Outside of the healthcare organizations and government bodies, there were consulting and IT companies, professional bodies, and patient groups as well as media that were involved or interested in NCRS implementation. Figure 3 depicts the main stakeholders and the institutional processes of NCRS implementation (evidence provided in Appendix D), which are elaborated next.

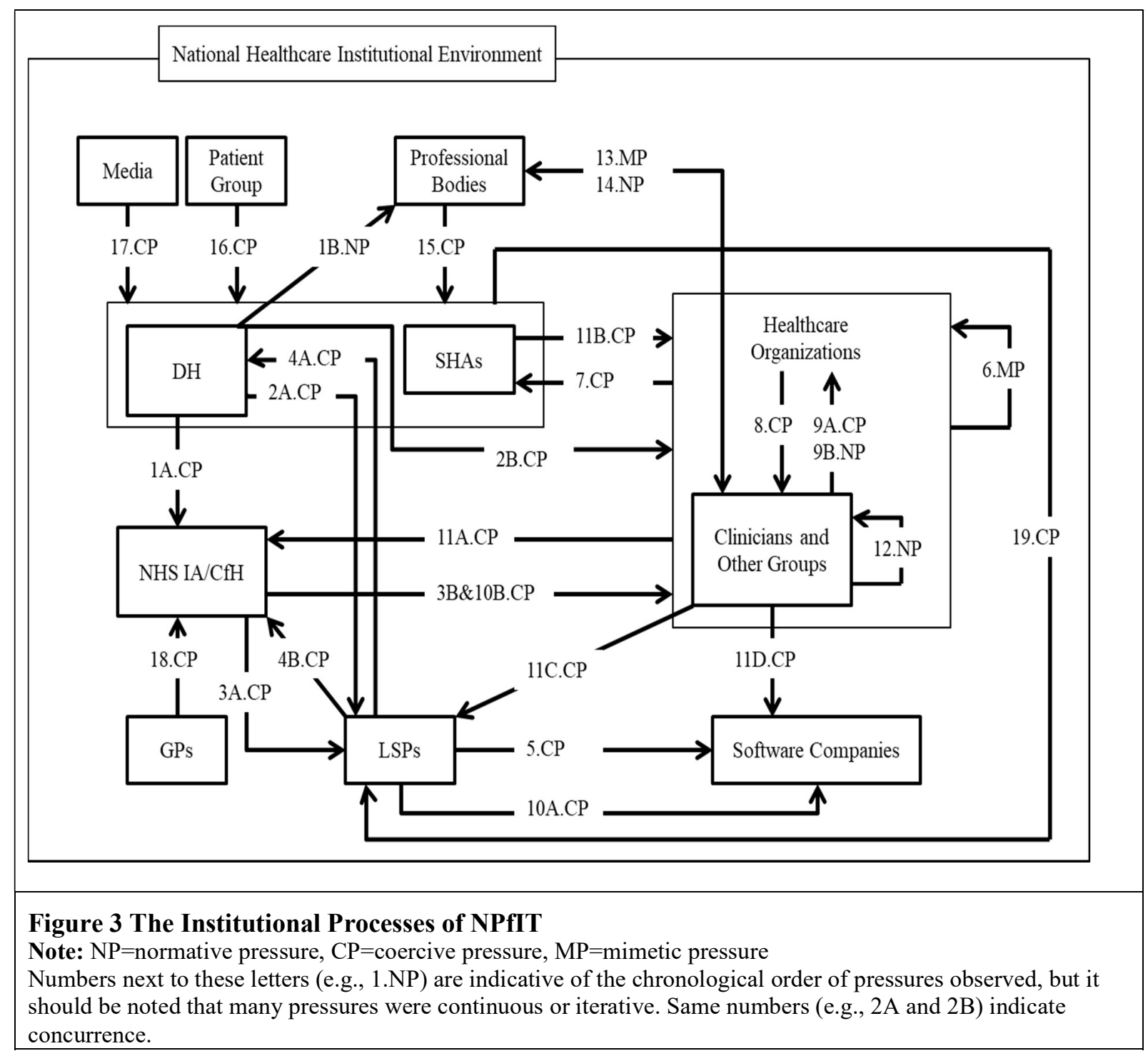


DH - Department of Health; GPs - General Practices; LSP - Local Service Providers; NHS IA/CfH - NHS

Information Authority and later NHS Connecting for Health; SHAs - Strategic Health Authorities

DH exercised coercive pressure (1a.CP) on the NHS IA/CfH through legislation, policies, regulations, contracts and appointments, and normative pressure (1b.NP) on professional bodies by publicizing benefits of shared EHR for patient care.

To deliver NPfIT's vision, England was split into four regions for service deployment. Despite this, the scope and complexity of proposed systems meant only very large organizations with substantial resources could bid for contracts. These contracts were awarded to four main 'solution providers' (Accenture, British Telecom, CSC, and Fujitsu), referred to in subsequent literature as Local Service Providers (LSPs). Formal delivery contracts were signed between DH and LSPs, which created obligations for LSPs (coercive pressure 2A.CP) and secondary/tertiary healthcare organizations (coercive pressure 2 B. $C \boldsymbol{P}$ ) in relation to systems' delivery and adoption. As a healthcare professional explained: "the reason why we implemented (NCRS) was because of tremendous government pressure for us to go live. If we didn't have that pressure, we probably would not have gone live" [Clinical lead, Site 2]. CfH managed the contract and was thus able to exert coercive pressure on LSPs $(3 \boldsymbol{A} . \boldsymbol{C P})$ and secondary/tertiary healthcare organizations (3B.CP). Via contracts, legitimacy and (contested) power to deliver standardized software was transferred to LSPs.

However, LSPs felt the contracts were very constraining and punitive, and as one interviewee noted, "they [the LSP] were not in a position to stand up to CfH'. The contract, initially hailed as a great achievement for the NHS, shifting risk from the NHS to the suppliers, is now widely considered as being at the root of many problems with the program. This is, at least partly because "that contract was not written by the NHS, it's not managed by the NHS it's managed by this organization called Connecting for Health and it's only loosely connected to what the NHS actually need or want”. [LSP Manager] As the IT Manager in Site 1 explained: “The milestones in the plan were set as a contractual milestone so we weren't allowed to alter those. What was quite difficult was we had to work backwards from those milestones ... that were probably going to be unachievable, but we had to work within the constraints of that contract". LSPs also exerted coercive pressures on $\mathrm{DH}(4 \boldsymbol{A} . \boldsymbol{C P})$ and $\mathrm{CfH}(4 \boldsymbol{B} . \boldsymbol{C P})$ through contract re-negotiations and legal challenges; Fujitsu initiated a successful legal battle when its contract was terminated. LSPs contracted out many aspects of NCRS implementation (design, coding and deployment) to software companies, exerting on them coercive pressures (5.CP) to deliver systems. Two different approaches to NCRS implementation were adopted: (1) iSoft's attempted development of bespoke software for the NHS, called Lorenzo, and (2) CSC's customization of an established, large-scale packaged American product, Cerner's Millennium.

Incentive mechanisms, such as a $\mathrm{CfH}$ administered Deployment Incentive Fund (DIF) of $£ 1$ million to each early adopter organization, helped recruit initial sites. Trusts which chose early adoption were also motivated by the desire to raise the power and urgency of their claims and more specifically to "get the biggest 
impact on designing the things that work and don't work' [Clinical Lead, Site 3]. They also sought to increase their legitimacy as leading organizations. Program leadership hoped isomorphic (mimetic) pressures (6.MP) would lead to all sites implementing NCRS following the lead of early adopter sites. According to our interviewee "a platform was created to learn from the places that got it wrong and the places that got it right and to sort of use that as a vehicle for securing trouble free deployment through the rest of the program. [IT Manager, Site 2] However, as initial sites struggled to implement (struggles eagerly reported by the media) exchanges of experiences, according to Healthcare Professional, Site 1, were suppressed "Once we had gone live with us then I thought, it's part of my job now as a part of the NHS community to make sure other hospitals don't suffer. I wasn't allowed to tell other hospitals how bad it was".

Furthermore, some interviewees believed the decision to become an early adopter was made by the regional administrative bodies, the Strategic Health Authorities (SHAs), rather than the hospitals: "our SHA chose two sites to be the first adopters of Cerner ... From the trust perspective it felt very much it was decision outside of their control" [IT Manager, Site 1]; "there was almost no choice in taking on the system" [Healthcare Professional, Site 2]. This indicates the existence of coercive pressure of SHA on hospitals which lacked semiautonomous status (given to foundation trusts (FT)) (7.CP).

Software providers' contractual arrangements were with the Local Service Providers (LSPs), not the trusts receiving NCRS, the LSPs themselves were contracted by DH. Thus, trusts had little formal power in terms of contractual arrangements and it was difficult for them to exert direct influence on software providers. Clinicians felt they had limited influence over service design, and experienced coercive pressures (8.CP) from hospital administration to adopt NCRS, as a nurse explained: "I think people have used it because they've had to and it's been, you know, it's a directive from the trust, and it's quite clear that that's what we have to do" [Healthcare Professional, Site 5]. During SHA led consultations, clinicians tried to exert coercive (9A.CP) and normative (9B.NP) pressures on their organizations (trusts' management). A SHA manager complained that "doctors have control to a large extent over what goes on in the trust and they are very powerful and they like to do it their way". Clinicians and other stakeholder groups in sites implementing the de-novo Lorenzo had more scope for software customization. Sites regularly received new system builds and had to test them extensively, raising any issues they wanted addressed.

Both CfH and the LSPs exercised their power to prioritize issues healthcare organizations raised or even to reject them on the grounds that software met design specification. LSPs tried to limit customization by encouraging (or pressurizing) standardized site practices. Some LSPs facilitated meetings between trusts hoping 'ruthless standardization' could be achieved bottom up (through mimetic pressure 6.MP). However, growing problems, led LSPs and CfH to exert coercive pressure (10A.CP \& 10B.CP) on both hospital managers and clinicians to get them to sign off software even if it was sub-optimal. A Healthcare Professional in Site 2 bemoaned: "We are being pressured into accepting suboptimal things and they [software developers] are 
being pressured to develop and deliver suboptimal products just because of the type pressure that they are under."

Clinicians in turn exercised their power over the process by invoking safety concerns (coercive pressures on CFH, SHA, LSP and Software companies - 11A.CP, 11B.CP, 11C.CP and 11D.CP) in order to postpone or abandon implementation. One software developer suggested: "the trusts always have the supplier over a barrel". However, trusts' power and urgency of claims varied over time and depended on unfolding events. An interviewee suggested that once a trust signed off the system, system providers would concentrate their efforts on the next implementation site, and ignore their needs. "Where you were in the plan determined how quickly you got out to supplier resources and that was definitely obvious. That is the downside of the National Programme, isn't it? They will always put the focus on the early sites." [IT Manager, Site 1]. Clinicians' requests, it appeared, in comparison with other hospital employees, were seen as (relatively) urgent, given their perceived power in NCRS implementation. Administrative staff had less power to directly oppose or ignore the system but could exercise it indirectly, e.g., by taking sick leave.

Stakeholders sometimes had more than one role, e.g., a nurse could receive additional system training to become a 'super-user' (effectively a trainer or a support person), helping others to learn the system. In some sites, super-users took active roles in implementation. Some senior clinicians were appointed as national clinical leads, the core of a network of people who could communicate the NPfIT vision and present its products to frontline NHS staff. In creating clinical leads and super-users the governing agencies attempted to legitimize implementation efforts to clinicians. Such professionals, through their role as mediators between the system and the users, gained power and urgency. They could also become a source of normative pressures (12.NP) exercised on other medical staff. Many clinicians, however, felt these clinical engagement efforts were superficial, given their exclusion from decision-making at the start of the program when decisions were being made about the nature and functions of the records, locus of control and implementation strategies. "They needed to come down a few layers and get people working with the clinicians from day one" [Healthcare Professional, Site 1].

Relations between stakeholders were characterized by complex inter-dependencies, tensions and conflicting expectations. Healthcare staff reflections suggested problems arose from the conflict between the market logic of private companies implementing systems and medical professionalism logic. LSPs were perceived as focused on product delivery and "not really caring about the product itself". Some felt LSPs politically prioritized support for sites seen as important (e.g., due to exposure in the media). However, LSPs and software companies felt they were working under extremely tough contracts to deliver the "mother of all systems" (as expressed by one of the interviewees from an LSP). The interviewee described his organization as "an engineering company. So we are fundamentally about getting stuff working, delivering it". Whilst acknowledging some positive aspects of $\mathrm{CfH}$ leadership, the interviewee complained that $\mathrm{CfH}$ "have got a very 
different mindset, you know, there are fundamentally different, we are fundamentally about delivery, and Connecting for Health [...] are about negotiating contracts". This illustrates that different institutional logics co-existed with market and medical professionalism logics. We label those engineering logic (exhibited by some software providers) and bureaucratic / administrative logic (of $\mathrm{CfH}$ ). EHR development was perceived as highly institutionalized by different stakeholders: “...it takes much longer to do anything than you think it's going to take and there's so many people involved, so many committees involved to get anything done at the supply side" [IT Manager, Site 4] "Everything has to be specified, everything has to be written down, when it comes back it has to be multiply tested, it has to be fitted into a framework, it has to be assessed against every other national service, I'm surprised they get anything to be honest." [Software Developer, Software Company].

Over the program's life, stakeholders' attributes, positions, and attitudes evolved. Although some accepted the system and were getting used to it, the majority struggled. Professional organizations (e.g., the British Medical Association (BMA) and Royal Colleges), became a source of mimetic pressure (13.MP) on clinicians (by amplifying dissatisfaction within the community) and normative pressure (14.NP) on clinicians (by issuing statements advising them to oppose NCRS implementation). Thus, mimetic pressures rather than supporting NCRS deployment worked against it. With time, professional bodies, patient groups, and the media exercised coercive pressure (15-17.CP) on DH to abandon NPfIT, sometimes citing security and privacy concerns. Constant media criticism of the program affected other stakeholders too, including software developers: because a lot of things aren't in our direct control a lot of the bad press if you like impacts us quite heavily yet it's not in our gift if you like to do a huge amount about it. [Software Developer, Software Company]. Many hospitals delayed their implementation of NCRS. Interestingly, in general, over the program's duration there was a high level of support for the idea of EHRs, but less for this instantiation.

In the case of primary care, where GP practices, independent contractors to the NHS, had freedom over system choice, a plan for a single strategic GP solution was abandoned following GP representations (coercive pressure 18.CP). CfH allowed GP practices to procure systems that met a set of minimum requirements.

Meanwhile, the $\mathrm{CfH}$ underwent a series of organizational and leadership changes over its existence. Its legitimacy and powers were curtailed in 2007 when responsibility for local delivery of the program transferred to SHAs, although $\mathrm{CfH}$ retained overall responsibility for implementation activities. However, this new approach, called National Local Ownership, did not solve existing problems but introduced new ones. Local decision making was not achieved as individual trusts were under SHA leadership. Furthermore, rather than dealing with one organization $(\mathrm{CfH})$, LSPs had to deal with several SHAs, who had the power to sign off systems (coercive pressure 19.CP), as explained by a LSP Manager: "Our life is much harder since the SHAs came along. [...] So if we produce a design deliverable for something originally Connecting for Health would have approved that, so there would be one place, they would approve it on behalf of all of the NHS in our 
cluster. We now have six discreet SHAs, each of whom want to approve it". After increasingly critical reports from the National Audit Office (NAO 2006; 2008; 2011) a formal process for dismantling NPfIT was announced in September 2011 when a new Coalition Government came to power. Costs and benefits of NPfIT are difficult to pinpoint and depend on what is included. In 2013, the Department of Health forecast total costs of $£ 9.8$ billion and benefits of $£ 10.7$ billion. However, as of $2012,98 \%$ of estimated benefits were still to be realized and it is uncertain if they will, whilst contract costs may rise (NAO, 2013).

Our research indicates considerable inter-site variation in NCRS implementation and its influence on work practices. Of 377 sites in which NCRS implementation was expected by the end of 2010, only 78 had begun the process of implementing the systems. Even then, most implementations have been of patient administration systems with limited clinical functionalities. Despite this, we argue that NPfIT should not be seen as a total failure, as a national IT infrastructure has been delivered and many of the programs that formed part of this service, including the Electronic Prescription Service (EPS) and SCR remain today, or have been updated. These exploit the large installed base of primary care computer systems, coupled with services provided by NHS N3 network and the Spine. Isomorphic pressures resulted in some standardization of practices. Part of the installed base that supported the NPfIT, and continues to support its successor programs are standards developed for data transfer. Furthermore, organizational learning that took place should not be discounted. As Robertson et al. (2010, p.29) argue: "the complexities in scaling up from implementation of local small-scale systems to national systems for electronic health records are now far better understood." We also note that post-NPfIT the government commitment to EHR, and more generally, to digitalize the NHS remains (DH, 2012). Although the technologies underpinning EHR and the strategies to implement it might be very different now, the notion that IT-enabled change in healthcare is necessary has taken hold not only at the government level but also in (at least some) healthcare organizations.

\section{CASE COMPARISON BETWEEN SINGAPORE AND ENGLAND}

We compare implementation efforts of national EHR systems in Singapore (NEHR) and in England (NCRS), highlighting both their similarities and differences. They show similarity in some aspects of the healthcare systems and challenges faced, but differ in their institutional environments prior to their national EHR program implementations, their stakeholder involvement, and their institutional processes during program implementation. We elaborate on these similarities and differences below.

\subsection{Healthcare Systems}

First and foremost, in both Singapore and UK, primary care is mainly provided through private GPs while acute care is largely provided through the public hospitals. However, NHS in England has contracts with GPs for their provision of free services, whereas in Singapore citizens pay for primary care from GPs mainly by themselves. 
Second, Singapore is considered highly efficient in healthcare provision according to the Bloomberg index ${ }^{16}$ with high longevity, while spending only $4.92 \%$ of its GDP on healthcare. By the same index, UK performed moderately (ranked 21 out of 55 countries) and spent $9.12 \%$ of its GDP on healthcare. Third, both countries possess central coordinating agencies in healthcare, i.e., $\mathrm{MOH}$ and MOHH in Singapore, and DH and the NHS England in England, which are responsible for managing healthcare resources and national EHR programs. In addition, since UK has a larger population and area, there are also regional agencies responsible for healthcare resources management, such as SHAs and PCTs. The central coordinating agencies in both countries applied "top-down" implementation strategies for national EHR.

\subsection{Institutional Environment before EHR Implementation}

Even prior to EHR implementation, there were differences in the political environment and continuity surrounding both programs. Although there was political stability in England, with the Labour government in power between 1997-2010, NPfIT was "met with cross-political party disagreements about the nature and scope of the Programme" Currie (2012, p. 242-243), reflecting a hostile political setting for the program. This was compounded by discontinuities in NPfIT's leadership, and re-organizations of the NHS and its governing bodies. Following a critical mass of negative National Audit Office reports (NAO 2006, 2008, 2011) as well as pressures from different stakeholders, NPfIT was dismantled when a new government came to power. In Singapore, continuity in the national government and in $\mathrm{MOH}$ management, allowed NEHR to progress on its planned trajectory even after key transitional events, which included the change of the health minister in 2011 and members of the MOHH NEHR management team in 2014. Throughout NEHR implementation, the initial buy in and support of $\mathrm{MOH}$ never wavered.

Second, these two countries also differed in their historical IT infrastructure for healthcare, which influenced their EHR system design choices. Prior to the National Programme for IT (NPfIT) a range of initiatives had attempted to introduce health informatics use in England. Specifically, public acute care had adopted a range of electronic patient record $\left(\mathrm{EPR}^{17}\right)$ systems although there were few agreed standards, and uptake was patchy. GP practices and community pharmacies supplying services to the NHS had also adopted health informatics systems. In this sense, NPfIT had ambitious goals of procuring and integrating many IT systems and infrastructures (Campion-Awwad et al., 2014; NAO, 2011) and implementing shared EHR was arguably NPfIT's most complex task. Furthermore, the combined size of the numerous NHS trusts was many times that of Singapore. By implementing NPfIT across such a large geographical area, the scale and complexity of the program increased significantly (Hendy et al., 2005). Therefore, the plan to 'reap and replace' all the existing EPRs and related systems in acute care with a new 'mother of all systems' and develop a single strategic solution for primary care was challenging to execute.

\footnotetext{
${ }^{16} \mathrm{https} / /$ www.bloomberg.com/news/articles/2016-09-29/u-s-health-care-system-ranks-as-one-of-the-least-efficient

${ }^{17}$ EPR here is equivalent to Electronic Medical Record (EMR) in the Singapore case.
} 
In contrast, whilst HIT systems in Singapore were to an extent fragmented, most patient records were stored in only 1 of 2 EHR systems (Eclipsys and CPSS). This made consolidation of information through the 2 regional clusters i.e., NHG and SingHealth, while challenging, a much simpler task than that faced by England. This was especially true given that both were under MOHH's governance. Coupled with the decision that NEHR was not to replace existing EMRs but 'ride on top of them', linking with them meant that national efforts occurred on a smaller scale with far less technical and non-technical complexity than NPfIT. Other factors that helped overcome fragmentation issues revolved around the simpler, flatter nature of Singapore and existing Health IT infrastructure in hospitals. Besides, before NEHR, there was an earlier integration effort, the electronic medical record exchange (EMRX) between clusters, although it only allowed document exchange. Furthermore, since there was quite limited adoption of EMR systems in the private sector, such as GP clinics, MOHH faced less challenge in integrating different legacy systems among these private stakeholders. $\mathrm{MOH}$ and $\mathrm{MOHH}$ attempted to promote NEHR among these private stakeholders through IT-enablement programs, which were directly linked to NEHR system.

Third, the healthcare governance structures of both countries differ, which also led to differences in their national EHR project organization. The NHS has a highly fragmented organizational structure and work practices vary between its organizations. One of our interviewees suggested that the problem with NPfIT was with its underlying assumption that there was "this thing called NHS" [a cohesive organization, with clear governance structures] and that all people would gravitate to the program and accept "all being the same" [Director of Programs and Strategy, site 3]. Due to its governance structure, NPfIT had to involve a complex network of stakeholders with different roles and responsibilities, which evolved over time. For example, originally, NPfIT solutions for acute and primary care were delivered by regional Local Service Providers (LSPs). At the outset of the NPfIT program implementation of the CRS was conducted by Connecting for Health (CfH). However, by 2007, as the program progressed, oversight moved to a localized model, with SHAs providing oversight of implementation as part of the National Local Ownership Programme, although contract management remained with CfH. LSPs therefore had to respond to requests from regional Strategic Health Authorities rather than the national $\mathrm{CfH}$.

In contrast, as explained by the MOHH senior manager, NEHR "was planned, designed and managed, top-down from here (MOHH)", which underscores the simpler, flatter healthcare organizational structure in Singapore. Specifically, there were 2 hierarchal layers, with $\mathrm{MOH}$ at the highest level, followed by $\mathrm{MOHH}$, the latter being the holding company of all public healthcare assets includes statutory boards that oversee different aspects of healthcare. Indeed, it was the focal stakeholder responsible for NEHR delivery. Furthermore, MOHH's subsidiary Integrated Health Information Systems (IHIS), that consolidated all public healthcare IT assets and manpower in healthcare organizations, helped $\mathrm{MOHH}$ facilitate the system integration work for NEHR project. Therefore, although in both countries, there existed central agencies responsible for designing 
and delivery the EHR systems, such as CfH for the NPfIT and MOHH for NEHR, with commercial solution providers, MOHH, through IHIS, had a more direct involvement in designing the EHR systems than CfH did. Conversely, IT staff in healthcare organizations were more directly involved in designing EHR from the start, than in England.

In addition, the differences in healthcare system structures also contributed to the differences in their EHR project organizations. Particularly, national EHR programs in both countries were centrally funded, with the key systems and IT infrastructure provided for free to healthcare organizations. However, unlike the UK, where the healthcare organizations are largely funded by the NHS, Singapore's primary care is dominated by private GP clinics. In Singaporean primary care, there was little IT infrastructure prior to NEHR, and even after the instigation of NEHR the government did not fully fund the primary care systems that would need to be linked to NEHR. Table 1 shows a comparison of the institutional context of the EHR implementation in both countries. 


\begin{tabular}{|c|c|c|}
\hline Category & Narrative: Singapore and England & Implications for EHR implementation in the two countries \\
\hline $\begin{array}{l}\text { Country } \\
\text { context }\end{array}$ & $\begin{array}{l}\text { England's population is approximately } 10 \text { times Singapore's, at } 52.6 \\
\text { million and area approximately } 18 \text { times greater at } 130,265 \mathrm{~km}^{2}\end{array}$ & $\begin{array}{l}\text { Much greater number of healthcare providers in England, } \\
\text { having implications for governance, number and type of } \\
\text { systems in use. }\end{array}$ \\
\hline $\begin{array}{l}\text { Healthcare } \\
\text { provision: } \\
\text { structure and } \\
\text { autonomy of } \\
\text { providers }\end{array}$ & $\begin{array}{l}\text { Both countries have a mix of public and private providers but acute care } \\
\text { is largely provided by public hospitals. Simpler and flatter healthcare } \\
\text { organizational structure in Singapore. In England, NHS organizations are } \\
\text { heterogeneous with different work practices. The trend towards } \\
\text { decentralization of decision making means that many of the trusts have } \\
\text { their own budgets and increasing levels of autonomy. }\end{array}$ & $\begin{array}{l}\text { Structures in Singapore more suited to top down } \\
\text { implementation process than in England. Heterogeneity of } \\
\text { English NHS organizations makes integration and } \\
\text { standardization more challenging. }\end{array}$ \\
\hline $\begin{array}{l}\text { Existing IT } \\
\text { infrastructure } \\
\text { before EHR }\end{array}$ & $\begin{array}{l}\text { Mix of paper-based and electronic record in both countries with limited } \\
\text { interoperability. In Singapore most patient records stored in } 1 \text { of } 2 \text { EHR } \\
\text { systems. In England fragmented IT and proliferation of legacy systems. }\end{array}$ & $\begin{array}{l}\text { Challenging context in both countries, in terms of lack of } \\
\text { standardization and interoperability, but more so in England. }\end{array}$ \\
\hline $\begin{array}{l}\text { Project } \\
\text { organization }\end{array}$ & $\begin{array}{l}\text { Programs in both countries are overseen by Health Ministry/Department. } \\
\text { In Singapore, } 2 \text { layers of governance (MOHH and its sub-body IHIS); } \\
\text { both responsible for designing and delivering of NEHR together with a } \\
\text { private consortium. In England more fragmented governance structures } \\
\text { that evolve over time including regional bodies. CfH - organization in } \\
\text { charge of the program delivery having less direct involvement in } \\
\text { designing the systems than MOHH in Singapore. }\end{array}$ & $\begin{array}{l}\text { In Singapore centralized control over the implementation of } \\
\text { EHR was maintained making integration through } \\
\text { standardization more achievable. In England efforts to impose } \\
\text { it were thwarted. }\end{array}$ \\
\hline $\begin{array}{l}\text { Funding and } \\
\text { Incentives }\end{array}$ & $\begin{array}{l}\text { Programs in both countries were centrally funded, with the key systems } \\
\text { and IT infrastructure provided for free to public healthcare organizations, } \\
\text { together with some technical and process support. }\end{array}$ & $\begin{array}{l}\text { England: Reluctance of healthcare organizations to spend time } \\
\text { and money for implementation of unproven (even if free) } \\
\text { system } \\
\text { Singapore: Despite incentives most of the private provides did } \\
\text { not take up the system (during the period covered here). }\end{array}$ \\
\hline $\begin{array}{l}\text { Delivery of } \\
\text { systems }\end{array}$ & $\begin{array}{l}\text { Both countries adopted a top-down implementation model, supplemented } \\
\text { by bottom-up design efforts. In England (at least initially) the plan is to } \\
\text { 'reap and replace' all the existing EHRs and related systems in acute care } \\
\text { with new 'mother of all systems'. In Singapore NEHR is designed to } \\
\text { 'ride on top' of the existing EMRs and to be accessed directly through } \\
\text { those systems or a Web portal. }\end{array}$ & $\begin{array}{l}\text { In England, stakeholders increasingly reluctant to abandon } \\
\text { their existing (and working) systems for a promised (but not } \\
\text { tested) new system for the greater good of integration. The plan } \\
\text { for primary care to develop a single strategic solution is quickly } \\
\text { abandoned. More flexible strategies in Singapore contributed to } \\
\text { greater stakeholder acceptance. }\end{array}$ \\
\hline Stakeholders & $\begin{array}{l}\text { In both countries there were three main sets of stakeholders directly } \\
\text { involved in the project: administrative bodies overseeing and running the } \\
\text { project, healthcare organizations and commercial solution providers, but } \\
\text { in England these were more diverse and in addition other stakeholders } \\
\text { became influential as the project progressed. }\end{array}$ & $\begin{array}{l}\text { Greater diversity of stakeholders in England, than in Singapore, } \\
\text { creates additional challenges for project management. }\end{array}$ \\
\hline
\end{tabular}




\subsection{Stakeholder Involvement and Institutional Processes during EHR Implementation}

Through our analysis, we found that during the implementation of NEHR and NCRS, different forms of isomorphism were driven by the key presence of normative, coercive, and mimetic pressures in the institutional environment, exercised top-down, bottom-up and horizontally. In both countries coercive pressures were exercised top-down from Health System Administrators on organizations responsible for the delivery of the programs ( $\mathrm{CfH}$ and $\mathrm{MOHH})$, and through those - on commercial solution providers, healthcare organizations, and by management of those on individuals. Those pressures were 'soft' and included financial incentives for early adopter sites, 'free' systems for all public providers (with software paid for centrally, but in England trusts bearing the costs of implementation, such as training and changeover processes), and 'hard', such as legislation (e.g., requiring trusts to have electronic health records, to report data which required such systems in place). In both countries, strong, top-down coercive pressures gave rise to bottom-up pressures by clinicians on healthcare integrators and commercial solution providers. However, those pressures varied in type and strength, and the way they interacted dynamically differed in the two countries. Ultimately they shaped results of the implementation efforts in different ways.

In Singapore, as the central public agency managing healthcare assets, $\mathrm{MOHH}$ played an important role in achieving isomorphism. On one hand, MOHH was influenced by normative pressures from public healthcare providers to improve the design of NEHR, which further benefited the implementation of NEHR. On the other hand, it applied coercive pressures on various groups of healthcare providers to adopt NEHR. Unlike a "singular" form of isomorphism (i.e., all healthcare organizations adopting a similar IT platform to connect to NEHR), we observed different mechanisms of achieving isomorphism from MOHH, each confined to a particular care sector.

First, in the Singapore public healthcare sector, access to NEHR was needed to get to each APH's EMR. By employing coercive pressure, MOHH was able to enforce the use of NEHR among APHs and make them contribute their EMR data to NEHR. In turn, doctors and CMIOs in APHs exerted normative pressures on MOHH to enhance the design of NEHR. This was uniform across all the RHS clusters. As other public providers (e.g., polyclinics) were twinned to their respective healthcare cluster's APH's EMR system (because of their past SingHealth / NHG affiliation and the present RHS clusters), there was similar integration of these providers. Also, as a part of the vertical integration in each RHS, community hospitals were able to extend their respective APH's EMR systems.

Furthermore, our analysis suggests that when public agencies attempt to co-opt autonomous organizations, such as in Singapore when MOHH brought GP clinics into the fold, in addition to exerting coercive pressures directly through subsidies, agencies can exert such pressures through softer approaches, such as integrating funds to support integration of applications with the EHR web portal. Also, for different types of provider organizations, there could be different strategies and systems, e.g., CLEO for GP clinics 
and NHELP for nursing homes. Based on the initial adoption of NEHR among these stakeholders (i.e., GPs and nursing homes), MOHH selected exemplar GPs and NHs to exert mimetic pressures on other parties (GPs and NHs) within the same sector. These different forms of isomorphism reflect the complexity of such a longitudinal program seeking to balance the interests of diverse stakeholders.

In England, through contracting arrangement, $\mathrm{DH}$ enabled $\mathrm{CfH}$ to exert coercive pressures to oversee the delivery of NPfIT. By managing the contracts of delivering NPfIT, CfH could exert coercive power on NHS organizations and the regional administrative Strategic Health Authorities (SHAs). For example, initial deployment of NPfIT solutions to acute care settings involved the selection of sites by SHAs and deployment of coercive pressure from SHAs and DH.

As in Singapore, different mechanisms of achieving isomorphism were pursued for different sectors (with different types of pressures applied and diverse systems offered to primary, mental and acute health) but in England those evolved significantly over time (e.g. local implementation plans were introduced in the latter parts of the program). However, unlike in Singapore, coercive pressures from government agencies often failed, counteracted by pressures from other stakeholders. The key difference was the ability of the professional bodies (such as BMA and Royal Colleges) in England to exert coercive pressures directly upon $\mathrm{DH}$ and $\mathrm{CfH}$ (e.g., BMA made calls to stop NCRS), and indirectly through normative pressures on clinicians (e.g., BMA advised its members to reject the system), who then employed coercive pressure on $\mathrm{CfH}$ and managers in healthcare organizations (through either explicit or implicit refusal to use the system and workarounds). The mechanisms of opposition employed by clinicians were the rhetoric of data and patient safety, whilst some administrative staff engaged in passive resistance. Patients groups and other pressure groups exerted normative/coercive pressures on administrators of health system and healthcare integration (DH and SHA) and media turned the public opinion against the NPfIT, giving a platform to dissatisfied voices. Commercial solution providers responded to pressures by either leaving the program, fighting the contract terms in court, or seeking to re-negotiate the contract. Hence, the employment of coercive pressures in the form of punitive contracts, at least in this case, was detrimental to the implementation effort.

Softer coercive pressures, such as incentives, had some success in improving the take up of EHR systems (particularly within primary care). However, soft incentives did not work in all circumstances. Although our research shows that the Deployment Incentive Fund for acute trusts had played a role in some trusts agreeing to be early implementer sites, those positive effects were not lasting, countered by bottomup pressures. As early adopters struggled, healthcare organizations followed a 'wait and see' approach. Thus, unlike in Singapore, mimetic pressures between acute trusts had negative effects on adoption in England.

Further, although in England, clinicians were seconded to NPfIT to represent clinical staff, those appointments came after key procurement decisions were made. Subsequent efforts to engage clinicians did not 
alleviate their belief they were not "involved" in setting NPfIT's direction (Currie, 2012). Our research indicates that clinical engagement and more broadly user engagement was problematic, at least partly due to contractual arrangements, complex supply chains, and formalized communication channels between hospitals, local service providers, software suppliers and $\mathrm{CfH}$. In contrast, in Singapore, we noted that doctors representing different clinical interest groups were engaged very early on during the initial NEHR planning phase and continued to be so throughout subsequent phases. Also, they were separated into five task forces representing different clinical interests such that NEHR could be a system "for clinicians by clinicians" (MOHH, 2010; Muttitt et al., 2012).

In our research, tensions between different, often conflicting, institutional logics were identified as posing challenges to NPfIT implementation. Our findings suggest that stakeholders were influenced by their immediate organization's institutional logics (e.g., institutional logics of a leading teaching hospital that aims to set 'best practice') and that of their professions' 'logics' (norms and behaviors). Both were strongly related to their professional identity. It would be simplistic, however, to assume all managers adhered to the same logic and were motivated by the same interests (Pouloudi et al. 2016). Our study revealed that IT managers in healthcare organizations often aligned themselves (at least partially) with healthcare professionals rather than $\mathrm{CfH}$ management. This supports Boonstra's et al. (2017) finding that in hospital IT implementation IT staff accommodated polarization between medical professionalism and the managerial logic. Stakeholders were able to effectively exercise power through calls to their own institutional logics, to exploit these to support their own interests. This created an environment in which there was continual re-modelling of the scope of the program. However, as the notion of stakeholder legitimacy and urgency suggest, the application of pressures are defined by timeliness of effort, and the context of application. Thus, during the deployment of the system, the acute care trust could exert coercive pressure on the LSP to influence the design of the systems. However, once an acute care trust signed off system this source of coercive pressure was lost. This led to frustration and contributed to dissatisfaction in the NPfIT implementation.

Although in the Singapore case, we found different institutional logics among various stakeholders, i.e., professionalism logic of doctors and managerialism logic of MOHH managers, our analysis suggests that there were solutions to mitigate or even resolve the challenges brought on by competing institutional logics. The key mitigators in the Singapore case were the CMIOs, who were senior doctors familiar with IT. Working closely with other doctors in their institutions, as well as being convinced of NEHR's value in obtaining efficiencies, they espoused both professionalism and managerialism logics (i.e., they played a role of 'boundary spanners', individuals who are able to facilitate the sharing of knowledge by connecting two or more groups of people separated by location, hierarchy, or function (Levina \& Vaast, 2005), and, in our case, also embracing different logics). Thus, CMIOs were able to bridge communication gaps between the central coordinating public agency, $\mathrm{MOHH}$, and NEHR's direct users, e.g., doctors/clinicians. Since they were powerful and legitimate in both 
groups, they could exert both coercive and normative influences during NEHR design and adoption, thus playing an important role in facilitating the process.

In this regard, Singapore's decision of having Chief Medical Information Officers (CMIOs) in key public care institutions (e.g., APHs) championing NEHR helped manage such institutional logics differences during its implementation. This was corroborated by our interviewees consistently highlighting the critical roles that APH CMIOs played in bridging gaps between clinicians and IT professionals. Their inputs helped define NEHR so that it was clinically relevant and in the process, they acted as mediators managing potentially competing institutional logics as part of their assigned change management roles. As the result the two logics were not in direct opposition to each other with regard to NEHR, and equilibrium was eventually achieved. In England clinical leads co-opted into administrative body $(\mathrm{CfH})$, to bridge managerialism and medical professionalism logics, either became disillusioned with the program and the nature of clinical engagement and left the post, or were unable to bring others to support the program. Different logics of managerialism, medical professionalism, as well market and engineering logics espoused by some private solution providers and bureaucratic logics of healthcare administrative bodies continued to be in conflict. Particularly, although the idea of EHRs was viewed positively by the majority of healthcare professionals, its particular manifestation, NCRS, was increasingly seen as detrimental to day-to-day patient care, and hence conflicting with medical professionalism logic, and thus to be resisted. The bureaucratic logic of $\mathrm{CfH}$ was seen as obstructing implementation and adoption of NCRS. Table 2 shows a comparison of the stakeholder interactions and institutional pressures in the two countries. 


\begin{tabular}{|c|c|c|c|}
\hline $\begin{array}{l}\text { Analytical } \\
\text { concepts }\end{array}$ & Narrative: Singapore and England & $\begin{array}{l}\text { Implications for EHR in the two } \\
\text { countries }\end{array}$ & Theoretical contributions \\
\hline $\begin{array}{l}\text { Dynamics } \\
\text { and groups } \\
\text { of } \\
\text { stakeholder } \\
\text { interactions }\end{array}$ & $\begin{array}{l}\text { Stakeholder composition } \\
\text { In both countries, there were four key groups of stakeholders: 1) } \\
\text { agencies responsible for health system administration, e.g., DH and } \\
\text { SHAs in England and MOH in Singapore; 2) central coordinating } \\
\text { agencies managing national EHR program, i.e., CfH in England and } \\
\text { MOHH in Singapore; 3) healthcare organizations; and 4) commercial } \\
\text { solution providers. } \\
\text { In both countries, authority and resources passed from health system } \\
\text { administration agencies to central coordinating agencies for national } \\
\text { EHR programs. From those, MOHH and CfH drew power and } \\
\text { (contested, at least in England) legitimacy to deliver EHRs. In } \\
\text { England, professional organizations, patients groups and media also } \\
\text { became influential stakeholders. } \\
\text { Role of central coordinating agencies } \\
\text { In both countries, central coordinating agencies managed contracts } \\
\text { with the commercial solution providers for EHR implementation. In } \\
\text { Singapore, MOHH subsidiary IHIS, specialized in system integration } \\
\text { and implementation, was responsible for the collaboration with } \\
\text { commercial solution providers limiting their influence over the } \\
\text { system design and implementation. } \\
\text { In England, CfH oversaw the implementation process, negotiating } \\
\text { between healthcare organizations and solution providers, but did not } \\
\text { take an active part in EHR design. IT managers and staff based in } \\
\text { healthcare organizations had less involvement in the initial design of } \\
\text { EHR than in Singapore. Contractual arrangements limited the ability } \\
\text { of healthcare organizations to directly interact with commercial } \\
\text { solution providers and to negotiate EHR design. This curtailed their } \\
\text { power over solution providers, but also resulted in exercising power } \\
\text { using safety argument as a last resort. } \\
\text { Involvement of healthcare professionals } \\
\text { MOHH and CfH attempted to engage healthcare professionals in } \\
\text { EHR programs, but in England this was problematic (and initiated } \\
\text { too late). In Singapore, MOHH managed to enroll the support of IT }\end{array}$ & $\begin{array}{l}\text { In Singapore, even though the } \\
\text { systems were designed and } \\
\text { deployed by commercial solution } \\
\text { providers, the involvement of } \\
\text { IHIS helped MOHH develop a } \\
\text { better understanding of the } \\
\text { technical solution and hold tighter } \\
\text { control over it. } \\
\text { In England, contractual } \\
\text { arrangements led to } \\
\text { dissatisfaction of healthcare } \\
\text { stakeholders, IT staff and } \\
\text { commercial solution providers. } \\
\text { Interactions between media, } \\
\text { patient groups and professional } \\
\text { bodies reinforced resistance to } \\
\text { NCRS. Clinician groups in } \\
\text { healthcare organizations } \\
\text { supported by the collective efforts } \\
\text { of professional bodies were able } \\
\text { to resist governing agencies to } \\
\text { implement EHR. This did not } \\
\text { occur in Singapore. }\end{array}$ & $\begin{array}{l}\text { When clinicians exercise } \\
\text { coercive rather than normative } \\
\text { pressure on the central } \\
\text { coordinating agency along with } \\
\text { the collective support of their } \\
\text { professional bodies, the role of } \\
\text { the agency in managing EHR } \\
\text { implementation may be } \\
\text { compromised. This may lead to } \\
\text { unstable dynamics of the } \\
\text { opposing forces and eventual } \\
\text { abandonment of the system. In } \\
\text { contrast, if institutional } \\
\text { conditions exist to take into } \\
\text { account normative pressures } \\
\text { exerted by clinicians to } \\
\text { iteratively improve the system, } \\
\text { this may result in a positive } \\
\text { cycle of opposing pressures and } \\
\text { eventual equilibrium in the } \\
\text { system implementation when all } \\
\text { parties are satisfied with it. } \\
\text { When there is an agency, such as } \\
\text { IHIS, specialized in EHR } \\
\text { implementation, comprised of IT } \\
\text { staff from healthcare } \\
\text { organizations but allied to the } \\
\text { central coordinating agency } \\
\text { (such as MOHH), and directly } \\
\text { working with commercial } \\
\text { providers to shape EHR, this can } \\
\text { reduce the power of the } \\
\text { commercial solution providers } \\
\text { and enable the central } \\
\text { coordinating agency to exercise }\end{array}$ \\
\hline
\end{tabular}




\begin{tabular}{|c|c|c|c|}
\hline & $\begin{array}{l}\text { employees in hospitals and CMIOs - senior doctors with technical } \\
\text { knowledge. Feedback from healthcare professionals shaped EHR } \\
\text { design. In England, different healthcare organizations had disparate } \\
\text { systems' requirements, but the goal of delivering standardized } \\
\text { software limited their scope for customizing EHR to their needs. }\end{array}$ & & $\begin{array}{l}\text { better control over the EHR } \\
\text { implementation process. }\end{array}$ \\
\hline $\begin{array}{l}\text { Institutional } \\
\text { pressures }\end{array}$ & $\begin{array}{l}\text { Top-down institutional pressures } \\
\text { In both countries, top-down coercive pressures were exercised by } \\
\text { administrators on organizations responsible for the delivery of the } \\
\text { programs, and through those - on commercial solution providers, } \\
\text { healthcare organizations, and by management of those on individuals. } \\
\text { Those pressures were 'strong' (e.g. contractual arrangements or } \\
\text { legislation) or 'soft' (e.g. incentives). Coercive pressures on primary } \\
\text { care were 'softer' than on acute care, reflecting their respective } \\
\text { private and public status. Top-down normative pressures were } \\
\text { exercised in both countries through the appeal for the need of shared, } \\
\text { standardized EHR to support healthcare integration, to deliver better } \\
\text { and more efficient healthcare. } \\
\text { Bottom-up institutional pressures } \\
\text { Bottom-up normative pressures both in Singapore and England } \\
\text { were exerted by clinicians on healthcare integrators, managers and } \\
\text { commercial solution providers. Key difference was that in England } \\
\text { normative pressures morphed into bottom-up coercive pressures. } \\
\text { Pressure groups and media exerted coercive pressures on the program } \\
\text { administrators. In Singapore, counter pressures from clinicians were } \\
\text { much weaker, and were exercised through lower take up of NEHR } \\
\text { but over time were largely addressed. } \\
\text { Horizontal institutional pressures } \\
\text { In England, horizontal normative pressures were exercised by } \\
\text { clinical professional bodies on clinicians, whilst in Singapore by } \\
\text { CMIOs on clinicians within the hospitals. In both countries mimetic } \\
\text { pressures were encouraged by government agencies through early } \\
\text { adopter initiatives. }\end{array}$ & $\begin{array}{l}\text { In both countries, strong, top- } \\
\text { down coercive pressures gave rise } \\
\text { to bottom-up, counter-pressures. } \\
\text { Bottom-up counter pressures were } \\
\text { much stronger in England and } \\
\text { gained momentum over time } \\
\text { resulting in stalled NCRS } \\
\text { implementation and abandoning } \\
\text { the NPfIT. } \\
\text { In both countries soft coercive } \\
\text { pressures (incentives) had some } \\
\text { success in improving take up of } \\
\text { the systems (more limited in } \\
\text { England). Mimetic pressures } \\
\text { between healthcare organizations } \\
\text { had positive effects on adoption } \\
\text { in Singapore and negative in } \\
\text { England. }\end{array}$ & $\begin{array}{l}\text { The choice of coercive pressures } \\
\text { should account for stakeholders' } \\
\text { power and status. Strong } \\
\text { coercive pressures tend to result } \\
\text { in counter-pressures and are } \\
\text { unlikely to be productive when } \\
\text { applied on autonomous, } \\
\text { powerful stakeholders. Soft } \\
\text { coercive pressures appear to be } \\
\text { more effective. } \\
\text { Normative, bottom-up pressures, } \\
\text { if not addressed, may morph into } \\
\text { bottom-up coercive pressures } \\
\text { (under enabling institutional } \\
\text { conditions) and through their } \\
\text { interactions strengthen each } \\
\text { other. Mimetic pressures may } \\
\text { have different effects, depending } \\
\text { on outcomes of implementation } \\
\text { by early adopters. }\end{array}$ \\
\hline $\begin{array}{l}\text { Institutional } \\
\text { logics }\end{array}$ & $\begin{array}{l}\text { Synthesis vs. conflict between different institutional logics } \\
\text { Managerialism and medical professionalism logics were present in } \\
\text { both countries. In Singapore, MOHH managers and CMIOs became } \\
\text { 'boundary spanners', straddling managerialism and medical }\end{array}$ & $\begin{array}{l}\text { In Singapore, NEHR was seen as } \\
\text { helping to provide better care and } \\
\text { hence supporting medical }\end{array}$ & $\begin{array}{l}\text { In an environment of conflicting } \\
\text { institutional logics IT } \\
\text { implementation is challenging } \\
\text { but can be made to work with the }\end{array}$ \\
\hline
\end{tabular}




\begin{tabular}{|l|l|l|l|}
\hline & $\begin{array}{l}\text { professionalism logics in order to pursue NEHR program. The two } \\
\text { logics were not in direct opposition to each other with regard to } \\
\text { NEHR. Normative pressures from hospital doctors influenced NEHR } \\
\text { design and enabled a better fit with healthcare professionals' needs. } \\
\text { In England, clinicians co-opted into CfH to bridge managerialism and } \\
\text { medical professionalism logics, did not convince clinicians to support } \\
\text { NCRS. Different logics continued to be in conflict. }\end{array}$ & $\begin{array}{l}\text { professionalism, as well as } \\
\text { managerialism logics. } \\
\text { In England, NCRS was seen as } \\
\text { detrimental to day-to-day patient } \\
\text { care, and conflicting with medical } \\
\text { professionalism logic, thus } \\
\text { resisted. Bureaucratic logic of } \\
\text { CfH was seen by some as } \\
\text { obstructing implementation and } \\
\text { adoption of NCRS. }\end{array}$ & $\begin{array}{l}\text { help of 'boundary spanners', } \\
\text { providing they maintain their } \\
\text { legitimacy. } \\
\text { medical professionalism logic if } \\
\text { it is seen as helping to provide } \\
\text { better care. }\end{array}$ \\
\end{tabular}




\subsection{Comparison Conclusion}

We presented cases of two countries in which broadly similar top-down strategies of EHR implementation resulted in different implementation outcomes. It is clear that the size of the country matters, influencing the scope and complexity of the programs. However, the difference between the institutional conditions run deeper than that, and include stakeholder heterogeneity and their different abilities to exercise power and claim legitimacy of their position in relation to EHR. Furthermore, existing IT infrastructure (before the program), project organization and delivery models, and the technological solutions proposed shape the attitudes and interactions/dynamics between stakeholders.

In Singapore, with few levels of hierarchy, a lesser number of public health organizations (APHs and polyclinics), relatively few legacy systems, and with a centralized public agency (MOHH) responsible for managing healthcare resources, with IHIS taking active role in working with private solution providers on designing the systems, it was possible to execute the national NEHR project fairly smoothly. The cluster- or region-based public healthcare system, which facilitates vertical integration, enabled MOHH to roll out NEHR for each Regional Healthcare Service. However, bringing all private healthcare providers on board and facilitating patient sharing of data still remains a challenge ${ }^{18}$.

In comparison, England's institutional field of healthcare was characterized by heterogeneous, powerful stakeholders, such as healthcare professionals and their representative bodies, semi-autonomous organizations with significant variations in practices (i.e., different ways of delivering care), and many different legacy systems. Those presented challenging conditions for healthcare integration through EHR. However, the differences between the two countries also include project organization and implementation models. An implementation model based on ideas of 'rip and replace' and 'ruthless standardization' that attempted to deliver a single information system that meets the needs of all local healthcare providers is now widely seen as very problematic (Clegg \& Shepherd, 2007; Currie \& Guah, 2007; Currie, 2012; Pouloudi et al., 2016). In England there was a mismatch between healthcare structures and the trend towards decentralization of decision making and the top-down nature of NCRS delivery. In contrast, although Singapore's aim was also to deliver integrated care, and the healthcare structure was more suited to top down implementation process, the implementation model allowed for existing IT systems to co-exist with NEHR (which was designed to 'ride on top of them'). We also note how the characteristics of technology influenced outcomes. Thus, in England more progress was made to implement NCRS in trusts that had Cerner-based software, rather than Lorenzo - which struggled to deliver a complex system de novo. Furthermore, other systems developed under NPfIT, such as the Electronic Prescription Service and

\footnotetext{
${ }^{18} \mathrm{http}: / /$ www.straitstimes.com/opinion/national-electronic-health-records-need-a-check-up
} 
Summary Care record were eventually adopted (although this has been a much slower process than initially anticipated).

The above points should not be conceptualized as static 'factors' but rather as evolving conditions that affected attitudes of stakeholders and dynamic interactions between them. Thus, it is in those interactions, with stakeholders influenced by and drawing on institutional logics, making conflicting claims regarding legitimacy of their views, and seeking to shape views and actions of each other, that the institutional pressures played out. Ultimately, in Singapore those pressures reached some sort of equilibrium, which refers to a state of balance or a stable situation, and facilitated the adoption of NEHR, whilst in England counter-pressures gained momentum over time and resulted in stalled or abandoned implementations of NCRS in England.

\section{IMPLICATIONS AND CONCLUSION}

\subsection{Theoretical Contributions}

This study adds to the extant literature through a comparative examination of the organizational and social processes during complex national healthcare integration projects. As noted in prior studies (Currie \& Finnegan, 2009), such forms of healthcare integration involve intricate organizational and social processes. However, it is a complex phenomenon (Currie, 2012) that has received relatively less research attention. Particularly, for Singapore, we believe this is the first piece of socio-technical research based on the NEHR program given its relative infancy, and its ongoing implementation, at the time of writing. Unlike Sinha et al.'s (2013) report, which provides a factual account of NEHR's progress through secondary sources, this research explores a broader range of issues and stakeholders, while applying two relevant theoretical lenses on both primary and secondary data sources. This can should aid future researchers' understanding of NEHR's progress during its formative years.

Additionally, this study contributes to institutional literature by complementing prior research in several ways. First, we reaffirm here that institutional forces (i.e., normative and mimetic) can indeed occur on an international, governmental basis. This was reflected in the travel of EHR ideas from Canada to Singapore through the overseas professionals engaged for NEHR. This also adds to an area of literature which has been under-researched (Kuipers et al., 2014). Second, apart from healthcare's two well-known institutional logics (Yeow \& Faraj, 2011) and the recognition that "de-professionalization" (one of the logics) can occur (Yang et al., 2013), we found that there can be stakeholders that embody a mix of both logics simultaneously. This was observed in MOHH managers and CMIOs in the Singapore case who straddled logics in order to pursue NEHR program while seeking buy-in from doctors. In the English case we also identified engineering and bureaucratic logics as an additional form of logics in this context. Third, we further develop Pouloudi's et al. (2016) contribution that illustrates how power of stakeholders affects how they exert their influence, not only at the organizational level, but also at the political (government 
agency level). Our research shows the type of pressures different stakeholders exerted on each other to influence decisions regarding EHR implementation both at the organizational and political levels, and how their power, legitimacy, as well as urgency of their claims may have affected their ability to do so.

We observed isomorphic pressures working in complex ways and reflecting different institutional logics. Both of our cases illustrate multiplicity of pressures on different levels and variety of responses (counter-pressures) resulting in different dynamics. Coercive, mimetic, and normative pressures were often bidirectional or multi-directional in our cases, usually vertical and top-down, e.g., applied by governmental agencies to healthcare stakeholders, and bottom-up e.g., exercised in response to those, but also horizontal, e.g., exercised across different healthcare institutions and professional associations, and within those. How and when such pressures are employed, what form they take (e.g., what type of incentives and mandatory requirements they entail) and how stakeholders respond to them (e.g. by building an opposition) influences the outcomes of change programs.

We illustrated that broadly similar coercive pressures (legislation) were applied in England and Singapore with different outcomes. This indicates that it is difficult to make over-reaching, generalized statements regarding strength and outcomes of isomorphic forces. They are intertwined with their institutional, geographical and temporal context, and with characteristics of the technology and strategies for its implementation. Our IS literature review revealed studies that found coercive pressures positively influencing IT adoption (Sherer et al., 2016) and reporting opposite effects (Klöcker et al., 2014), and mimetic pressures having positive effects on IT adoption (Sherer et al., 2016; Klöcker et al., 2014), whilst in our study of NCRS they were detrimental. Nevertheless, both cases have indicated that coercive pressures exercised directly through payments for EHR implementation (e.g., subsidies in Singapore, free software in England and additional payments to early adopters) can be successfully supported by other approaches such as indirect incentives or requirements. For example, in Singapore this involved funding for integration of systems with the EHR web portal, and in England this involved payments for GP outcomes which would necessitate provision of reports made much more easily with EHRs. Hence, we propose that the choice of coercive pressures should account for stakeholders' power and status. Specifically, strong coercive pressures tend to result in counter-pressures and are unlikely to be productive when applied on autonomous, powerful stakeholders. Soft coercive pressures appear to be more effective.

The English case illustrates that under enabling institutional conditions (such as the existence of historically powerful professions and semi-autonomous organizations) normative, bottom-up pressures, if not addressed, may morph into bottom-up coercive pressures. Over time, these may gain momentum, result in unstable dynamics, and ultimately adversely affect HIT implementation. The two cases show how mimetic pressures may have different effects, depending on outcomes of implementation by early adopters. 
Additionally, implementation of HIT may not necessarily be in conflict with healthcare professionalism logic, if HIT is seen as helping to provide better patient care and evolves in response to normative pressures from healthcare professionals. The Singapore case illustrates that in an environment of conflicting institutional logics IT implementation can be made to work with the help of 'boundary spanners'. However, in order to be effective they must be able to maintain legitimacy in the eyes of other stakeholders.

Further, this study adds to the HIT literature regarding perceptions of IT as enabler of national healthcare. Our cases show that despite different visions of EHR, repeated failures and continuing challenges of IT implementation, the notion of IT as an integral part of healthcare is becoming taken for granted, as expressed in the national policies we have reviewed (DH, 2012), and by our interviewees. As argued by Avgerou (2000), IT adoption in organizations is sustained through its own institutional forces. However, our studies in English hospitals reveals a 'duality' of attitudes - positive towards future idealized EHRs and often negative towards present offerings, reflecting an intriguing paradox on this salient issue.

Last, our proposed framework provides a useful conceptual tool for analyzing such complex IS implementations across multiple stakeholders. Additionally, its instantiations through the two disparate cases in our study offers a methodological contribution to the literature in the following ways. First, we propose categories for comparing HIT implementations in different countries (see Tables 1 and 2 and Appendix E). Second, we illustrate how multi-level analysis, building on individual accounts and on secondary sources (presenting organizational level perspective), may be undertaken in order to construct a picture of different types of stakeholders interacting and influencing each other dynamically. Although, ultimately, pressures are experienced and enacted by individuals (which may or may not belong to an organization) in national programs pressures are often expressed as expectations of what an organization should achieve (e.g., policy papers outlining targets), and are addressed through organizational strategies. Hence a study spanning those different levels can deliver additional insights. Third, since how stakeholders experience and respond to pressures is constructed in relation to other stakeholders, and since power relations between them are potentially unstable (Pouloudi et al. 2016), we propose that to understand those processes future research needs to include an ecology of stakeholders and multiplicity of pressures, and to show how dynamic interactions between them have developed over time, as is done in our study.

\subsection{Practical Implications}

We believe our study could support practitioners in enhancing healthcare integration through implementing a national EHR. Specifically, first, in addition to factors noted above in the England-Singapore comparison, our findings indicate that even within the same profession, different stakeholders had differing interests. In particular, doctors operating in public vs. private domains had to be engaged differently to gain their buy in. Government planners may be able to exert more influence on public healthcare providers (e.g., APHs) than private providers, as the public providers are reliant on them for funds, making the public sector a natural starting point for such 
an implementation program. However this strategy may not be appropriate for the private sector. Rather, planners may need to leverage their access to other resources (e.g., subsidies, patient pools) to produce an effective mix of incentives in order to encourage private providers to join the program. To ensure maximization of resources and long term gains, incentives and subsidies should achieve synergies with other initiatives (e.g., as part of an overall healthcare IT master plan). The key challenge for engaging the private sector is to gain a "critical mass" of healthcare providers so as to derive and demonstrate value for existing participants, thereby attracting new program participants.

Furthermore, central planners must consider change management issues within providers, as most providers have existing patient record systems that are to be replaced or integrated with or have paper-based records or both. Continuous engagement efforts would be needed to address diverse views of healthcare stakeholders even after initial implementation, to ensure sustained adoption. Key to this are stakeholders who are able to "see both sides" of the program such as the CMIO as described in the Singapore case. Additionally, patients are an integral part of this program as they ultimately stand to benefit from it. Their concerns such as confidentiality and privacy must be addressed visibly, in order to avoid setbacks as seen in England's case. This also requires an effective media management strategy for such initiatives.

This study also provides practitioners with insights on managing key stakeholders (e.g., clinicians). Clinicians are often direct users of IT and play an important role in the progress of EHR implementation. Therefore planners need to ensure that: 1) their clinical needs are adequately represented in the program from start to end; 2) mechanisms are in place to continually address feedback so as to facilitate improvements even after the program implementation; 3) potentially unclear areas (e.g., responsibilities and liabilities) introduced by integration should be clarified with the program's management, and clinicians informed and consulted. Nonetheless, it is recognized that there can be a diversity of opinions even within this group. As such, a systematic and consolidated approach to implement the above recommendations could be performed through professional bodies and associations, who are regarded as majority representative of doctors' needs. The problems of clinical engagement in England suggest that healthcare professionals need to be engaged early on when substantial decisions regarding the scope and mode of EHR implementation are being decided. Differences between healthcare professionals' expectations of the ideal system and the implemented one need careful ongoing management. Allied health professionals and administrative staff, although perhaps less powerful than doctors, are important for successful implementation and use of EHRs and thus should be included in engagement activities.

Finally, our findings indicate that where plurality in institutional arrangements exist (and to some extent are inevitable) different mechanisms of institutional pressures, e.g., based on incentives and flexible standards (Hanseth \& Bygstad, 2015) not ruthless standardization, and coercive targets that are linked to quality of care rather than particular technology (and thus allowing for plurality of EHR solutions) are likely to be more 
successful. In both the cases, the eventual systems that worked had a mix of technology solutions that were interoperable. EHRs that seek to deliver ambitious and comprehensive solutions are more risky and require sustained commitment from large number of stakeholders. However, when benefits are not immediately realizable such commitment is hard to secure. Thus, modular solutions that allow modular implementation strategies are more likely to succeed (Aanestad, \& Jensen, 2011). Going forward, EHRs are more likely to be envisaged as platforms on which different applications can be built and as portals to different applications, rather than as monolithic information systems. For example, both cases indicate a need to build analytics and patient-use applications on top of the EHR.

\subsection{Limitations and Future Work}

As with other research, this study also entails certain limitations. First, our integrative framework provides a means for exploring the phenomenon over time systematically, but does not provide predictive power as a variance model could. Nevertheless, the in-depth findings obtained from instantiating our framework across EHR implementations in England and Singapore have their own, significant value. Second, we chose two cases of national EHR implementations representing a largely public vs. a hybrid healthcare system. A natural extension in future work would be to examine EHR implementation in a largely private healthcare system, such as in the U.S. Additionally, we could be questioned about the applicability of our findings to IT integration in other industries. While we believe that many of the complex organizational and social issues discussed in this research are applicable to IT integration in general (such as deprecating existing IT systems), further validation would be required in other sectors.

Third, there are related aspects of research that we briefly mentioned but could not expand upon due to our existing focus. These include, understanding mechanisms by which institutional pressures emerge, elaborating on different approaches to EHR integration, and examining patient related issues (e.g., patient participation in innovation). These topics provide fruitful directions for future research. Other related topics to explore would be the implementation of IT enablement programs for a specific care sector e.g., those with lower IT maturity, such as nursing homes and GP clinics in Singapore. As each IT system brings with it its own set of business rules, it may be valuable to study the impact it has on providers' work arrangements, especially those that have not used electronic records within their practices before. This can help extend our knowledge beyond health IT systems within hospitals or other tertiary care organizations. Furthermore, the funding models and contractual arrangements of such programs need to be explored.

Healthcare information systems are in a state of constant development, with public projects emerging and being abandoned as political and organizational leadership changes. The research outlined here provides a framework for describing the institutional pressures and influences among stakeholders that we believe to be salient in determining the success of such efforts - in this case the development, implementation, and adoption of EHR. Additionally, in future, IS research will need to look beyond the delivery of EHR, to its application in 
use and the factors that shape such application. The findings from our research can provide a foundation for such future work.

\section{ACKNOWLEDGEMENTS}

We would like to thank the reviewers, the editor and Tony Cornford for their detailed and constructive comments. Their comments were crucial to improving the quality and clarity of our arguments. We are very grateful to all interviewees who kindly gave their time. We thank our colleagues in the CFHEP 005 project for their contribution to the evaluation. We appreciate the generous support and advice of the Independent Project Steering Committee overseeing this evaluation. We also thank the NHS Connecting for Health Evaluation Programme.

\section{ETHICS AND RESEARCH GOVERNANCE}

An NHS Ethics Committee classified CFHEP 005 project as a service evaluation (ref. 08/H0703/112). Informed consent from participating organizations and individuals was obtained. We also complied with local research governance requirements. All data has been anonymized and care has been taken to ensure that any quotes in this paper are not attributable to participating individuals.

\section{FUNDING}

The English case reports on the findings from a project commissioned by the NHS CFH Evaluation Programme (NHS CFHEP 005). The views expressed in this publication are those of the authors and not necessarily those of the NHS, the NHS CFH Evaluation Programme or the Department of Health. 


\section{REFERENCES}

Aanestad, M., \& Jensen, T.B. (2011). Building nation-wide information infrastructures in healthcare through modular implementation strategies. Journal of Strategic Information Systems, 20(2): 161176.

AcademyHealth (2010). Integration, concentration, and competition in the provider marketplace. http://studylib.net/doc/11579310/\%EF\%83\%A0-research-insights-integration-concentration--and-compe... (accessed 24/05/2018).

Accenture (2012). Singapore's journey to build a national electronic health record. https://www.accenture.com/no-en/ /media/Accenture/ConversionAssets/LandingPage/Documents/1/Accenture-Singapore-Journey-to-Build-National-ElectronicHealth-Record-System.pdf (accessed 06/05/2018)

Agle, B.R., Mitchell, R.K., \& Sonnenfeld, J.A. (1999). Who matters to CEOs? An investigation of stakeholder attributes and salience, corporate performance, and CEO values. Academy of Management Journal, 42(5): 507-525.

AHRQ (2014). Health information technology integration. http://www.ahrq.gov/professionals/preventionchronic-care/improve/health-it/ (accessed 24/05/2018).

Avgerou, C. (2000). IT and organizational change: An institutionalist perspective. Information Technology and People, 13(4): 234-262.

Azad, B., \& King, N. (2012). Institutionalized computer workaround practices in a Mediterranean country: an examination of two organizations. European Journal of Information Systems: 21(4), 358-372.

Bauchner, H., Berwick, D., \& Fontanarosa, P.B. (2016). Innovations in Health Care Delivery and the Future of Medicine. JAMA, 315(1): 30.

Baxter, R., \& Lewis, M.O. (2010). Organizational boundaries, industry fragmentation, and electronic personal health records, in Proceedings of the International Conference on Information Systems, ICIS 2010, Saint Louis, Missouri, 1627-1638.

Benson, T. (2002). Why general practitioners use computers and hospital doctors do not—Part 1: incentives. British Medical Journal, 325(7372): 1086-1089.

Boonstra, A., and de Vries, J. 2008. Managing Stakeholders around Inter-Organizational Systems: A Diagnostic Approach, The Journal of Strategic Information Systems (17:3), pp. 190-201.

Boonstra, A., Yeliz Eseryel, U., \& van Offenbeek, M. A. (2017). Stakeholders' enactment of competing logics in IT governance: polarization, compromise or synthesis? European Journal of Information Systems: 1-19. 
Brennan, S. (2005). The NHS IT project: The biggest computer programme in the world ... ever! Radcliffe: Abingdon, UK.

Brodbeck, K. (2012). Merger destiny: Synthesizing organizational and executive leadership change. Nurse Leader, 10(3): 29-32.

Bromley, P. \& Suárez, D.F. (2014). Institutional theories and levels of analysis: History, diffusion, and translation, in Schriewer, J., ed. Re-Conceptualising the Global/Local Nexus: Meaning Constellations in the World Society. Routledge/Taylor \& Francis, 139-159.

Brooks, C. (2010). Information technology and improving patient safety in Singapore hospitals: Turning ideas into action.

http://www.gs 1.org/docs/healthcare/events/091110/3 MOHHolidings Brooks.pdf (accessed 24/05/2018).

Campion-Awwad, O., Hayton, A., Smith, L., \& Vuaran, M. (2014). The National Programme for IT in the NHS, MPhil Public Policy, University of Cambridge.

Chen, C., Garrido, T., Chock, D., Okawa, G., \& Liang, L. (2009). The Kaiser Permanente electronic health record: Transforming and streamlining modalities of care. Health Affairs, 28(2): 323-333.

Clegg, C. \& Shepherd, C. (2007). 'The biggest computer programme in the world...ever!': time for a change in mindset? Journal of Information Technology, 22: 212-221.

CNA. (2014). IT helping to address Singapore's evolving healthcare needs: Gan. http://www.channelnewsasia.com/news/health/it-helping-to-address/1362576.html (accessed 24/05/2018).

Currie, W.L. (2012). Institutional isomorphism and change: The national programme for IT-10 years on. Journal of Information Technology, 27(3): 236-248.

Currie W.L. (2013) Health IT policy in the UK: The case of electronic health records. In: Michell V, Rosenorn-Lanng D, Gulliver S, Currie W, editors. Handbook of Research on Patient Safety and Quality Care through Health Informatics. Hershey, PA: IGI Global; 363-381.

Currie, W.L., \& Finnegan, D. (2009). Integrating healthcare with information and communications technology: Radcliffe Publishing.

Currie, W.L., \& Guah, M.W. (2007). Conflicting institutional logics: A national programme for IT in the organisational field of healthcare. Journal of Information Technology, 22(3): 235-247.

Currie, W.L., Finnegan, D.J., \& Koshy, M.A. (2011). Applying sense-making to integrated health IT: Renal care in the UK and Sweden, presented at AMCIS, Detroit.

DH (1997). The new NHS: Modern, dependable. Department of Health. Her Majesty's Stationery Office: London. 
DH (2002). Delivering 21st Century IT support for the NHS: National strategic programme. Department of Health. The Stationery Office: London.

DH (2012). The Power of Information: Putting All of Us in Control of the Health Care Information We Need. Department of Health. The Stationery Office: London.

DiMaggio, P.J., \& Powell, W.W. (1983). The iron cage revisited: Institutional isomorphism and collective rationality in organizational fields. American Sociological Review, 48(2): 147-160.

Doolin, B. (1999). Sociotechnical networks and information management in health care. Accounting, Management and Information Technologies 9(2): 95-114.

DOS (2016). Population trends. http://www.singstat.gov.sg/docs/default-source/default-documentlibrary/statistics/visualising_data/population-trends2016.pdf (accessed 24/05/2018)

Du, L., \& Lu, W. (2016). U.S. health-care system ranks as one of the least-efficient. https://www.bloomberg.com/news/articles/2016-09-29/u-s-health-care-system-ranks-as-one-ofthe-least-efficient Bloomberg (accessed 24/05/2018).

EHA (2014). Eastern Health Alliance ("EHA") Data Protection Policy. http://www.easternhealth.sg/Documents/EH\%20Alliance\%20Data\%20Protection\%20Policy.pdf (accessed 24/05/2018).

Evans, J.M., Baker, G.R., Berta, W., \& Barnsley, J. (2013.) The evolution of integrated health care strategies. Advances in Health Care Management, 15: 125-162.

Fareed, N., Bazzoli, G.J., Mick, S.S.F., \& Harless, D.W. (2015). The influence of institutional pressures on hospital electronic health record presence. Social Science \& Medicine, 133: 28-35.

Foucault, M. (1979). Discipline and punish: The birth of the prison (A. Sheridan, Trans.). Harmondsworth: Penguin.

Freeman, R.E. (2010). Strategic management: A stakeholder approach: Cambridge University Press. Gopalakrishna-Remani, V., Jones, R.P., \& Wooldridge, B.R. (2016). Influence of institutional forces on managerial beliefs and healthcare analytics adoption. Journal of Managerial Issues, 28: 191-209.

Hanseth, O., \& Bygstad, B. (2015). Flexible generification: ICT standardization strategies and service innovation in health care. European Journal of Information Systems, 24(6), s 645- 663.

Hawley, A. (1968.) Human ecology in: Sills, DL (ed.) International Encyclopedia of the Social Sciences: New York: Macmillan.

Hendy, J., Reeves, B.C., Fulop, N., Hutchings, A., \& Masseria, C. (2005). Challenges to implementing the national programme for information technology (NPfIT): A qualitative study. BMJ, 331(7512): 331-336. 
Hodge, T. (2011). National electronic health record perspectives: Singapore.

http://infowayconnects.infoway-inforoute.ca/2011/03/21/national-electronic-health-recordperspectives-singapore/ (accessed 24/05/2018).

Hodgson, G.M. (2006). What are institutions? Journal of Economic Issues, 40(1), 1-25. doi: $10.2307 / 4228221$.

Hui, P.C. (2012, Sept 18). 43 public health-care institutions 1 patients' database. The Straits Times. Hung, S.-Y., Chen, C., \& Wang, K.-H. (2014). Critical success factors for the implementation of integrated healthcare information systems projects: An organizational fit perspective. Communications of the Association for Information Systems, 34(1): 39.

IDA. (2006). Integrating healthcare, empowering patients: Report by the iN2015 healthcare and biomedical sciences sub-committee: Infocomm Development Authority of Singapore.

Jackson, C.L., Nicholson, C., Doust, J., Cheung, L., \& O'Donnell, J. (2008). Seriously working together: Integrated governance models to achieve sustainable partnerships between health care organisations. Medical Journal of Australia, 188(8): S57.

Jensen, T.B., Kjærgaard, A., \& Svejvig, P. (2009). Using institutional theory with sensemaking theory: A case study of IS implementation in healthcare. Journal of Information Technology, 24(4): 343353.

Klecun, E. (2016). Transforming healthcare: Policy discourses of ICT and patient-centred care. European Journal of Information Systems, 25(1): 64-76.

Klein, H. K., \& Myers, M. D. (1999). A set of principles for conducting and evaluating interpretive field studies in information systems. MIS Quarterly, 23(1): 67-93.

Klöcker, P., Bernnat, R. \& Veit, D. (2014). Implementation through force or measure? How institutional pressures shape national eHealth programs, in European Conference on Information Systems (ECIS) (Tel Aviv, Israel, 2014).

Kohli R. and Tan, S.S.L. (2016). Electronic health records: How can IS researchers contribute to transforming healthcare? MIS Quarterly, 40(3): 553-573.

Kuipers, B.S., Higgs, M., Kickert, W., Tummers, L., Grandia, J., \& Van der Voet, J. (2014). The management of change in public organizations: A literature review. Public Administration, 92(1): $1-20$.

Kwee, H.H. (2009). Transforming healthcare delivery in Singapore. SMA News: Ministry of Health.

Lamb, R. (2006). Alternative paths toward a social actor concept, in AMCIS 2006 Proceedings, 493.

Lee, M. (2014). NHELP for nursing homes to curb lapses. http://www.asiaone.com/health/nhelp-nursinghomes-curb-lapses. (accessed 24/05/2018) 
Levina, N., \& Vaast, E. (2005). The emergence of boundary spanning competence in practice: implications for implementation and use of information systems. MIS Quarterly, 29(2), 335-363.

Lockett, A., Currie, G., Waring, J., Finn, R., \& Martin, G. (2012). The role of institutional entrepreneurs in reforming healthcare. Social Science \& Medicine, 74(3): 356-363.

Luna-Reyes, L.F., \& Gil-García, J.R. (2011). Using institutional theory and dynamic simulation to understand complex e-Government phenomena. Government Information Quarterly, 28(3): 329345.

Marchington, M., \& Vincent, S. (2004.) Analysing the influence of institutional, organizational and interpersonal forces in shaping inter-organizational relations. Journal of Management Studies, 41(6):1029.

McLeod Jr, A.J., \& Clark, J.G. (2009). Using stakeholder analysis to identify users in healthcare information systems research: Who is the real user? International Journal of Healthcare Information Systems and Informatics (IJHISI), 4(3): 1-15.

Mekonnen, S. M., \& Sahay, S. (2008). An Institutional Analysis on the Dynamics of the Interaction between Standardizing and Scaling Processes: A Case Study from Ethiopia. European Journal of Information Systems, 17(3): 279-289.

Mignerat, M., \& Rivard, S. (2009). Positioning the institutional perspective in information systems research. Journal of Information Technology, 24(4): 369-391.

Miles, M.B. and Huberman, A.M. (1994). Qualitative Data Analysis: An Expanded Sourcebook, 2nd ed., Sage Publications, Newbury Park, CA.

Mitchell, R.K., Agle, B.R., \& Wood, D.J. (1997). Toward a theory of stakeholder identification and salience: Defining the principle of who and what really counts. Academy of Management Review, 22(4): 853-886.

MOHH (2010). Our National Electronic Health Records Clinical Advisory Group Co-Chairs welcome you. HealthFIT.

Mok, K.H., \& Forrest, R. (2008). Changing governance and public policy in East Asia: Routledge.

Muttitt, S. (2008). Towards a National Electronic Health Record: A view from 10,000 feet up and 10,000 miles away.

Muttitt, S., McKinnon, S., \& Rainey, S. (2012). Singapore's National Electronic Health Record (NEHR): The journey to 2012 and beyond. Paper presented at HIMSS.

NAO (2006). The National Programme for IT in the NHS: National Audit Office.

NAO (2008). The National Programme for IT in the NHS: Progress since 2006: National Audit Office.

NAO (2011). The National Programme for IT in the NHS: An update on the delivery of detailed care records systems: National Audit Office. 
NAO (2013). Review of the final benefits statement for programmes previously managed under the National Programme for IT in the NHS: National Audit Office.

Noor, K.B. (2008). Case study: A strategic research methodology. American Journal of Applied Sciences, $5(11)$.

OECD (2013). What future for health spending? OECD Economics Department Policy Notes (19).

Office for National Statistics (2011). Statistical Bulletin, 2011 Census: Population Estimates for the United Kingdom, March 2011. London

Okma, K.G., Cheng, T.M., Chinitz, D., Crivelli, L., Lim, M.K., Maarse, H., \& Labra, M.E. (2010). Six countries, six health reform models? Health care reform in Chile, Israel, Singapore, Switzerland, Taiwan and The Netherlands. Journal of Comparative Policy Analysis, 12(1-2): 75-113.

Oliver, C. (1991). Strategic responses to institutional processes. Academy of Management Review, 16(1): 145.

Pache, A.-C., \& Santos, F. (2013). Inside the hybrid organization: Selective coupling as a response to competing institutional logics. Academy of Management Journal, 56(4): 972-1001.

Petrakaki, D., \& Klecun, E. (2015). Hybridity as a process of technology's 'translation': Customizing a national Electronic Patient Record. Social Science \& Medicine, 124: 224-231.

Petrakaki, D., Klecun, E. \& Cornford, T. (2016). "Changes in healthcare professional work afforded by technology: The introduction of an electronic patient record in an English hospital” Organization, 23(2): 206-226.

Pouloudi, N., Currie, W., \& Whitley, E.A. (2016). Entangled stakeholder roles and perceptions in health information systems: A longitudinal study of the UK NHS N3 network. Journal of the Association for Information Systems, 17(2): 107-161.

Ramesh and Bali (2018). The healthcare system in Singapore. http://global-isasian.nus.edu.sg/index.php/healthcare-system-singapore/ (accessed 04/05/2018)

Rawlins, B.L. (2006). Prioritizing stakeholders for public relations. Institute for Public Relations, 1-14.

Reay, T., \& Hinings, C. R. (2009). Managing the rivalry of competing institutional logics. Organization Studies, 30(6), 629-652.

Robertson A., Cresswell K., Takian, A., Petrakaki, D., Crowe, S., et al. (2010). Implementation and adoption of nationwide electronic health records in secondary care in England: Qualitative analysis of interim results from a prospective national evaluation. BMJ, 341: c4564.

Scott, R., Ruef, M., Mendel, P. \& Carona, C. (2000). Institutional Change and Healthcare Organizations: From Professional Dominance to Managed Care. University of Chicago Press: Chicago and London 
Scott, W.R. (2005). Institutional theory: Contributing to a theoretical research program. Great minds in management: The Process of Theory Development, 460-485.

Sheikh A., Cornford T., Barber N., Avery A., Takian A. et al. (2011). Implementation and adoption of nationwide electronic health records in secondary care in England: final qualitative results from prospective national evaluation in "early adopter" hospitals. BMJ, 343:d6054.

Sherer, S.A., Meyerhoefer, C.D., \& Peng, L. (2016). Applying Institutional Theory to the Adoption of Electronic Health Records in the US. Information \& Management, 53(5): 570-580.

Shirey, M.R. (2012). Stakeholder analysis and mapping as targeted communication strategy. Journal of Nursing Administration, 42(9): 399-403.

Shum, E., \& Lee, C.E. (2014). Population-based healthcare: The experience of a regional health system. Ann Acad Med Singapore, 43(12): 564-565.

SingHealth. (2014). SingHealth Data Protection Policy. http://www.ndcs.com.sg/AboutUs/DataProtection/Documents/20140630\%20Singhealth\%20Grp \%20Data\%20Protection\%20Policy\%20Version\%201.pdf (accessed 24/05/2018).

Sinha, P., Sunder, G., Bendale, P., Mantri, M., \& Dande, A. (2013.) Singapore's NEHR. Electronic health record: Standards, coding systems, frameworks, and infrastructures, 259-266.

Sligo, J., Gauld, R., Roberts, V., \& Villa, L. (2017). A literature review for large-scale health information system project planning, implementation and evaluation. International Journal of Medical Informatics, 97:86-97.

Syal, R. (2013). Abandoned NHS IT system has cost £10bn so far. The Guardian. http://www.theguardian.com/society/2013/sep/18/nhs-records-system-10bn (accessed 24/05/2018).

Talbot-Smith, A. \& Pollock, A.M. (2006). The new NHS: A guide. Routledge: London.

Townley, B. (1997). The institutional logic of performance appraisal. Organization Studies, 18(2):261285.

UNPAN (2013). The United Nations Public Service Award. https://publicadministration.un.org/unpsa/Public_NominationProfile.aspx?id=903 (accessed $24 / 05 / 2018)$.

Walsham, G. (1993). Interpreting information systems in organizations. John Wiley \& Sons.

Walsham, G. (1995). Interpretive case studies in IS research: nature and method. European Journal of Information Systems. 4(2), 74-81.

Wanless D. (2002). Securing our future health: Taking a long-term view. Final report. London: HM Treasury; http://webarchive.nationalarchives.gov.uk/20090321152552/http://www.hmtreasury.gov.uk/consult_wanless final.htm (accessed 24/05/2018). 
Yang, Z., Kankanhalli, A., Ng, B.-Y., \& Lim, J.T.Y. (2013). Analyzing the enabling factors for the organizational decision to adopt healthcare information systems. Decision Support Systems, 55(3): 764 .

Yeow, A., \& Faraj, S. (2011). Microprocesses of healthcare technology implementation under competing institutional logics, in ICIS, Shanghai, 6, 1-10.

\section{Appendix A: Summary of Data Sources of Singapore Case (NEHR)}

\begin{tabular}{|c|c|c|c|}
\hline Sector & Organization & Role* & Source \\
\hline \multirow[t]{10}{*}{ Public } & Ministry of Health (MOH) & Senior Clinician & 5 \\
\hline & \multirow[t]{3}{*}{ Ministry of Health Holdings (MOHH) } & Senior Manager & 4 \\
\hline & & $\begin{array}{l}\text { Senior Clinician and IT } \\
\text { Advocate }\end{array}$ & 2 \\
\hline & & IT Manager & 13 \\
\hline & Agency of Integrated Care (AIC) & Senior Manager & 7 \\
\hline & \multirow{2}{*}{$\begin{array}{l}\text { Integrated Health Information Systems } \\
\text { (IHIS) }\end{array}$} & Senior Manager & 1 \\
\hline & & Senior Manager & 8 \\
\hline & \multirow{3}{*}{$\begin{array}{l}\text { Acute Public Hospitals (APHs) } \\
\text { - APH1 } \\
\text { APH2 }\end{array}$} & CMIO (APH1) & 11 \\
\hline & & Senior Manager (APH1) & 9 \\
\hline & & Manager (APH2) & 12 \\
\hline \multirow{4}{*}{$\begin{array}{l}\text { Private/Non } \\
\text {-profit }\end{array}$} & Polyclinics\# (P1) & Doctor & 3 \\
\hline & Polyclinics\# (P2) & Doctor & 6 \\
\hline & Community Hospital/Nursing Home & Doctor & 14 \\
\hline & General Practitioner (GP) Practice & Doctor (2) & 10,15 \\
\hline
\end{tabular}

\section{Appendix B: Evidence of Findings of the Singapore Case (NEHR)}

Source: Indicates the origin of the quote, this may be from a primary source (as numbered in Table 1) or secondary source.

\begin{tabular}{|c|c|c|}
\hline Pressure & Quote & Source \\
\hline \multirow[t]{2}{*}[1.\mathrm{CP}]{} & $\begin{array}{l}\text { - The ministry (MOH) here propagates the policies, works out a broad } \\
\text { funding, works with MOF (ministry of finance), MOHH then develops } \\
\text { specifications with user entities (which) then carry out instructions of } \\
\text { MOH. } \\
\text { - We (MOH) govern the process (NEHR) through the MOH community. }\end{array}$ & 5 \\
\hline & $\begin{array}{l}\text { - No, we (MOHH) were like an agent of MOH. So MOH said okay, we } \\
\text { pass to you (MOHH), subcontract to you, deliver. }\end{array}$ & 4 \\
\hline [2A. MP] & $\begin{array}{l}\text { - Slides showing comparisons and similarities of Singapore's MOHH } \\
\text { and Canada's Health Infoway organization. Modelling of MOHH's } \\
\text { Information System Division and proposed NEHR solution after } \\
\text { Canada's EHR system }\end{array}$ & Muttitt (2008) \\
\hline
\end{tabular}




\begin{tabular}{|c|c|c|}
\hline \multirow[t]{3}{*}{ [2B. NP] } & $\begin{array}{l}\text { - MOHH brought in Canadian consultants as part of the MOHH NEHR } \\
\text { IT team (Travels of ideas), which influenced the developments of the } \\
\text { NEHR project. }\end{array}$ & Muttitt (2008) \\
\hline & - There was a lot of foreign experts that came, Canada, Australia. & 3 \\
\hline & $\begin{array}{l}\text { - MOHH Publicity brochure about NEHR, showed NEHR team } \\
\text { composition of foreign staff members. }\end{array}$ & MOHH (2010) \\
\hline \multirow[t]{9}{*}{ [3A. NP] } & - What our clinicians need (based on their consultation with clinicians) & Brooks (2010) \\
\hline & $\begin{array}{l}\text { - More than } 200 \text { clinicians were engaged in driving the business and } \\
\text { information requirements of NEHR system. }\end{array}$ & $\begin{array}{l}\text { UNPAN } \\
(2013)\end{array}$ \\
\hline & - These doctors gave feedback. & 8 \\
\hline & $\begin{array}{l}\text { - In terms of NEHR, I am fairly involved with the folks at MOHH } \\
\text { regarding how to do, what to do and so on. }\end{array}$ & 10 \\
\hline & $\begin{array}{l}\text { - I was part of the summary care community, what do we want in the } \\
\text { summary care first page. } \\
\text { - That part I know was all ground feedback we used ground feedback, } \\
\text { this is what we want, we are talking about standardization, privacy, } \\
\text { confidentiality, all the x-rays. }\end{array}$ & 3 \\
\hline & - Formation of clinical task forces (hierarchy) & Muttitt (2008) \\
\hline & - Help clinicians contextualize/ make the IT system relevant to them. & 2 \\
\hline & $\begin{array}{l}\text { - They will specify and dictate their requirements on what they want, } \\
\text { right down to how things are displayed on screens. }\end{array}$ & 1 \\
\hline & $\begin{array}{l}\text { - I showed how you can do a national EMR... My argument was single } \\
\text { EMR, single database is way too expensive. And everybody must move } \\
\text { in the same movement, it's very painful and expensive...single } \\
\text { database... I thought was a better idea (reflects discussion process). }\end{array}$ & 7 \\
\hline [3B.NP] & $\begin{array}{l}\text { - The CMIO plays a pivotal role by providing critical clinical } \\
\text { directions and inputs on the requirements, design, implementation } \\
\text { and use of medical information. }\end{array}$ & 12 \\
\hline [3C. NP] & $\begin{array}{l}\text { - We [IHIS] played the middleware role and we also played the } \\
\text { operational, architectural [roles], because operationally how to } \\
\text { weave in NEHR into the operations. We provided that knowledge } \\
\text { about the ground operations for NEHR team. } \\
\text { - So our governance, what IHIS contributes is really the governance. } \\
\text { - So, then down there, project management teams, always involve IHIS } \\
\text { folks and the users together. }\end{array}$ & 8 \\
\hline [3D.CP] & $\begin{array}{l}\text { - IHIS then was tasked at that time to execute (implementing acute } \\
\text { - hospital EMR to community hospitals). } \\
\text { - which we implement (the EMR system that acute hospitals used) } \\
\text { - MOHH decides and provides a list of recommended suitable } \\
\text { organizations (for NEHR) to IHIS. There is a team at MOHH who } \\
\text { designed/ are the architects of NEHR, they are an IT team. They work } \\
\text { with the IHIS hospital supporting team to provide the technical } \\
\text { connectivity (hospitals). Concurrently, the MOHH team drives NEHR } \\
\text { efforts with healthcare organization user engagement. }\end{array}$ & 1 \\
\hline [3E.NP] & $\begin{array}{l}\text { - Designers of the NEHR need to know what information doctors use in } \\
\text { NEHR for reference. }\end{array}$ & 1 \\
\hline
\end{tabular}




\begin{tabular}{|c|c|c|}
\hline & $\begin{array}{l}\text { - Following the inception of IHIS, in } 2008, \text { we were } 600 \text { people then, } \\
500 \text { staff }+100 \text { contractors and these were all taken from the then IT } \\
\text { departments of NHG and SingHealth (two healthcare clusters). }\end{array}$ & \\
\hline \multirow[t]{2}{*}[4.\mathrm{CP}]{} & $\begin{array}{l}\text { - The Accenture led consortium are system integrators, more technical } \\
\text { in nature and they do the infrastructure and development of NEHR. }\end{array}$ & 1 \\
\hline & $\begin{array}{l}\text { - The contract to implement Phase } 1 \text { of Singapore's National Electronic } \\
\text { Health Record has been awarded to an Accenture-led consortium, } \\
\text { with target roll-out of the NEHR in April } 2011\end{array}$ & MOH 2010 \\
\hline [5A.NP] & $\begin{array}{l}\text { - Working with Accenture, MOHH invested in the development of a } \\
\text { goal-state architecture. }\end{array}$ & $\begin{array}{l}\text { Accenture } \\
2012\end{array}$ \\
\hline [5B.NP] & $\begin{array}{l}\text { - By using screen mock-ups of NEHR in clinician workshops, the team } \\
\text { in Singapore was able to identify which features and functionalities } \\
\text { appealed to end users. The project team engaged clinicians as early } \\
\text { as possible in the process, in order to understand their preferences } \\
\text { and help drive towards a simpler and more intuitive interface. }\end{array}$ & $\begin{array}{l}\text { Accenture } \\
2012\end{array}$ \\
\hline \multirow[t]{6}{*}{ [6A. CP] } & $\begin{array}{l}\text { - The public healthcare sector... fully owned by us (MOHH). The } \\
\text { minister can make a decision, and the family (public healthcare } \\
\text { institutions) has to comply... when the instruction or the policy } \\
\text { directions have been made at the government level, you're with it. }\end{array}$ & 4 \\
\hline & $\begin{array}{l}\text { - NEHR is free. Free to the provider, free to the patient and funded by a } \\
\text { capital grant from the government and to that extent, MOF (ministry } \\
\text { of finance). }\end{array}$ & 13 \\
\hline & $\begin{array}{l}\text { - Amongst others, the Ministry (MOHH through MOH) provide funding } \\
\text { assistance (to public hospitals). }\end{array}$ & 12 \\
\hline & $\begin{array}{l}\text { - It was planned, designed and managed, top-down from here (MOHH). } \\
\text { - MOHH team drives NEHR efforts }\end{array}$ & 4 \\
\hline & - MOHH administers the money. & 8 \\
\hline & - Stat body (MOHH) that is the effector arm of policies. & 5 \\
\hline \multirow[t]{2}{*}{ [6B. CP] } & $\begin{array}{l}\text { - SingHealth Institutions may handle personal data using IT platforms } \\
\text { and tools promulgated by MOH, MOHH or other like body including, } \\
\text { but not limited to the National Electronic Health Records ("NEHR") } \\
\text { system. SingHealth Institutions apply and require the application of } \\
\text { reasonable and defensible security and access controls in the use of } \\
\text { such systems, such that organisations other than the SingHealth } \\
\text { Institution treating or transacting with you have only such access as is } \\
\text { on a need to know basis for purposes and in a manner consistent with } \\
\text { this DPP (Data Protection Policy) and/or where (and to the extent) } \\
\text { necessary to meet your needs. }\end{array}$ & \multirow[t]{2}{*}{$\begin{array}{l}\text { EHA (2014); } \\
\text { SingHealth } \\
(2014)\end{array}$} \\
\hline & $\begin{array}{l}\text { - As healthcare providers, EHA (Eastern Health Alliance) Members } \\
\text { and/or its staff are subject to and regulated by various statutes and } \\
\text { regulations such as the Medical Registration Act, Singapore Medical } \\
\text { Council Guidelines etc. Additionally, special legislation may apply to } \\
\text { certain healthcare scenarios, }\end{array}$ & \\
\hline \multirow[t]{2}{*}{ [7A. NP] } & $\begin{array}{l}\text { - Every time they (MOHH) launch one version they make us test it. } \\
\text { - We basically told them no one was going to use it }\end{array}$ & 11 \\
\hline & $\begin{array}{l}\text { - The doctors said "No you cannot shutdown the EMRX" } \\
\text { - This thing [EMRX] to get so stuck in the whole mind-set to get stuck } \\
\text { in the workflow that they say no you cannot shut this off. }\end{array}$ & 4 \\
\hline
\end{tabular}




\begin{tabular}{|c|c|c|}
\hline [7B. NP] & $\begin{array}{l}\text { - They (CMIOs) will specify and dictate their requirements on what } \\
\text { they want, right down to how things are displayed on screens. } \\
\text { - They (CMIOs) are very involved in the process. }\end{array}$ & 1 \\
\hline \multirow[t]{2}{*}{ [7C. NP] } & $\begin{array}{l}\text { - They (CMIOs) are authority to convince/influence their fellow } \\
\text { colleagues (doctors). } \\
\text { - They (CMIOs) do the change management }\end{array}$ & 1 \\
\hline & - I (CMIO) am also supposed to be the change champion & 11 \\
\hline $\begin{array}{l}{[8 \mathrm{~A} / 8 \mathrm{~B} /} \\
8 \mathrm{C} / 8 \mathrm{D} \\
\mathrm{CP}]\end{array}$ & $\begin{array}{l}\text { - Now we are the one forcing them (GPS) if they want to link with } \\
\text { NEHR, not only you take from me, you need to give back. In order to } \\
\text { give back, you need to be electronic. } \\
\text { - They (NHs) will want to plug in because you've got only 20\% of the } \\
\text { pool, I've got } 80 \% \text { and as we integrate care, then... (patients are) } \\
\text { going to go out of the acute hospital boundaries right down to the } \\
\text { community. So if you don't plug in, you (will be left out) } \\
\text { - We are telling (GPs) them if you want to continue taking (subsidies) } \\
\text { you have to start giving in return (to NEHR) and you need to hook up. } \\
\text { - There were already other programs quite unrelated to CLEO. The } \\
\text { chronic disease management program which allowed Medisave to be } \\
\text { used. } \\
\text { - Then CHAS came in and these are the little goodies and different } \\
\text { grades if you are a very progressive clinic and you sign on to all these } \\
\text { programs, yes then reciprocal there is this IT system that is available } \\
\text { and we will subsidize a little bit of it to put it in place for you. That's } \\
\text { how you get it started. } \\
\text { - That's why the CHAS chronic disease is a very fundamental piece, } \\
\text { then yes, you join but if you join then you have to accept that this } \\
\text { (NEHR, IT systems) is part of this whole package of providing care } \\
\text { for your patients right? Because if you are not going to do it... you } \\
\text { don't get the patient, } \\
\text { - A lot of the schemes now they have been coming out the subsidies } \\
\text { schemes for the elderly is are all linked to this system (of which NEHR } \\
\text { is part of) } \\
\text { - The CHAS, the chronic management system, disease management } \\
\text { program and all that requires electronic submissions. So I way or } \\
\text { another - you going to have to buy yourself a desktop and you got to } \\
\text { put a system there to either through the web or you have a direct link } \\
\text { but you need to create that portal to submit information back to us. } \\
\text { Sooner or later and if you want these patients, then you have to do } \\
\text { this. }\end{array}$ & 4 \\
\hline \multirow[t]{5}{*}{ [9. MP] } & $\begin{array}{l}\text { - Sooner or later... if you (GPS) want these patients, then you have to } \\
\text { do this (be IT-enabled and use NEHR) } \\
\text { - Very progressive people who were ready to go }\end{array}$ & 4 \\
\hline & - Likeminded doctors who want(ed) to look after patients better & 3 \\
\hline & - When I started there was only 10 (GPs onboard NEHR). & 10 \\
\hline & $\begin{array}{l}\text { - Sees a selected group of general practitioners testing the platform in } \\
\text { their clinics. }\end{array}$ & Hui (2012) \\
\hline & $\begin{array}{l}\text { - Recently, electronic information exchange was extended beyond } \\
\text { private primary care and ... more than } 230 \text { general practitioner (GP) } \\
\text { clinics. }\end{array}$ & CNA (2014) \\
\hline
\end{tabular}




\begin{tabular}{|c|c|c|}
\hline & $\begin{array}{l}\text { - As of February 2015, about } 550 \text { (or } 37 \% \text { of 1,500) private GP clinics } \\
\text { have access to NEHR, up from about } 190 \text { in March last year. }\end{array}$ & MOH (2015) \\
\hline [10. MP] & $\begin{array}{l}\text { - What I [hospital senior manager] intend to do when we talk to the } \\
\text { nursing homes, we will bring along the nursing homes who have } \\
\text { already adopted NEHR to come and share with them the usefulness. } \\
\text { So I think it is easier to get one of the champion to sell rather than for } \\
\text { us. They will probably say what you know about NEHR, what you } \\
\text { know about the operations at the nursing homes who you think will } \\
\text { need. So I think the nursing homes who have used NEHR, voiced out it } \\
\text { is useful. So it is better for them to sell the thing }\end{array}$ & 9 \\
\hline
\end{tabular}

\section{Appendix C: Summary of Data Sources of England Case (NPfIT)}

\begin{tabular}{|l|l|l|}
\hline \multicolumn{3}{|l|}{ Table 5. Primary Data Sources for the England Case (NPfIT) } \\
\hline Sector & Organization & Role \\
\hline \multirow{4}{*}{ Private } & Local Service Provider & Manager (2)* \\
\cline { 2 - 3 } & Software Company & Software developer (2) \\
\hline \multirow{5}{*}{ Public } & Hospital trusts & Healthcare professional (14) \\
\cline { 3 - 3 } & & Clinical / IT lead (2) \\
\cline { 3 - 3 } & & IT specialist (1) \\
\cline { 3 - 3 } & & IT manager (8) \\
\cline { 2 - 3 } & & Manager (2) \\
\cline { 2 - 3 } & Strategic Health Authority & Manager (2) \\
\hline
\end{tabular}

* Number in brackets indicate number of people interviewed 


\section{Appendix D: Evidence of Findings of the England Case (NCRS): NPfIT}

\begin{tabular}{|c|c|c|}
\hline \multicolumn{3}{|c|}{ Table 6. Institutional Pressures } \\
\hline Pressure & Quote & Source \\
\hline$[1 \mathrm{~A} . \mathrm{CP}]$ & $\begin{array}{l}\text { - On } 1 \text { April 2005, the National Programme joined with the IS/IT } \\
\text { services from the NHSIA to form a single new organization - NHS } \\
\text { Connecting for Health. This implements one of the recommendations } \\
\text { from the Department of Health's review of its Arm's Length Bodies } \\
\text { (ALBs) - one of the first changes to be delivered. It means that NHS } \\
\text { Connecting for Health has the challenge of maintaining and running } \\
\text { existing IT services for the NHS, as well as bringing new ones to } \\
\text { fruition. [...] NHS Connecting for Health is formally part of the } \\
\text { Department of Health, but is managed as an ALB to ensure it has } \\
\text { flexibility of operation. }\end{array}$ & $\begin{array}{l}\text { NHS } \\
\text { Connecting } \\
\text { for Health } \\
(2005)^{19}\end{array}$ \\
\hline$[1 \mathrm{~B} . \mathrm{CP}]$ & $\begin{array}{l}\text { - Health policy documents and technology strategies at the time set out } \\
\text { the benefits of EHR and HIT more generally. }\end{array}$ & $\begin{array}{l}\text { Policy: DH } \\
\left(2000^{20} ;\right. \\
\left.2002^{* 1}\right) \\
\text { Strategy: } \\
\text { Burns } \\
(1998)^{22}, \text { DH } \\
\left(2001^{23} ;\right. \\
2002)\end{array}$ \\
\hline \multirow[t]{2}{*}{$\begin{array}{l}{[2 \mathrm{~A} . \mathrm{CP}]} \\
\& \\
{[2 \mathrm{~B} . \mathrm{CP}]}\end{array}$} & $\begin{array}{l}\text { - ... the contract was set out for the South, it constrained not just us but } \\
\text { probably the supplier as well in terms of us putting workable solutions } \\
\text { in locally } \\
\text { - We had to work within the constraints of that contract }\end{array}$ & $\begin{array}{l}\text { IT Manager, } \\
\text { Site } 1\end{array}$ \\
\hline & $\begin{array}{l}\text { - The reason why we implemented (NCRS) was because of tremendous } \\
\text { government pressure for us to go live. If we didn't have that pressure, } \\
\text { we probably would not have gone live. }\end{array}$ & $\begin{array}{l}\text { Clinical Lead, } \\
\text { Site } 2\end{array}$ \\
\hline \multirow[t]{2}{*}{$\begin{array}{l}{[3 \mathrm{~A} . \mathrm{CP}]} \\
\& \\
{[3 \mathrm{~B} . \mathrm{CP}]}\end{array}$} & $\begin{array}{l}\text { - Connecting for Health sits separately to influence both CSC [LSP] } \\
\text { and iSoft [Software Developer], yeah, because iSoft have delivered the } \\
\text { system against requirements specified by Connecting for Health. } \\
\text { - But actually that contract was not written by the NHS, it's not } \\
\text { managed by the NHS it's managed by this organization called } \\
\text { Connecting for Health and it's only loosely connected to what the } \\
\text { NHS actually need or want. }\end{array}$ & LSP Manager \\
\hline & $\begin{array}{l}\text { - The milestones in the plan were set as a contractual milestone so we } \\
\text { weren't allowed to alter those. What was quite difficult was we had to } \\
\text { work backwards from those milestones ... that were probably going to }\end{array}$ & $\begin{array}{l}\text { IT Manager, } \\
\text { Site } 1\end{array}$ \\
\hline
\end{tabular}

\footnotetext{
${ }^{19}$ NHS Connecting for Health (2005) "Better information better health NHS National Programme for IT Annual Report 2004-2005”. ${ }^{20}$ DH (2000). The NHS Plan. Department of Health, London: HMSO.

${ }^{21}$ DH (2002). Shifting the Balance of Power: the next steps. Department of Health, London: HMSO.

${ }^{22}$ Burns, F. (1998). Information for Health: an information strategy for the modern NHS 1998-2005. Leeds: Department of Health, NHS Executive.

${ }^{23} \mathrm{DH}$ (2001). Building the information core - implementing the NHS Plan. Department of Health.
} 


\begin{tabular}{|c|c|c|}
\hline & $\begin{array}{l}\text { be unachievable, but we had to work within the constraints of that } \\
\text { contract". }\end{array}$ & \\
\hline \multirow[t]{2}{*}{$\begin{array}{l}{[4 \mathrm{~A} . \mathrm{CP}]} \\
\& \\
{[4 \mathrm{~B} \cdot \mathrm{CP}]}\end{array}$} & $\begin{array}{l}\text { - It doesn't appear so far as I can tell. No, no we're not because we're } \\
\text { so late on everything that we owe them [Connecting for Health] } \\
\text { millions and millions and millions of pounds, so we are, we're kind of } \\
\text { not in a very strong position in terms of, we're not commercially in a } \\
\text { very strong position }\end{array}$ & LSP Manager \\
\hline & $\begin{array}{l}\text { Despite the view expressed by our interviewee re-negotiating contracts } \\
\text { with LSPS has proven a challenging task for CfH and DH with } \\
\text { contractors accused of contractual breaches tending to counter-sue. }\end{array}$ & $\begin{array}{l}\text { Campion- } \\
\text { Awwad et al. } \\
\text { (2014), House } \\
\text { of Commons } \\
\text { Public } \\
\text { Accounts } \\
\text { Committee } \\
\text { reports. }\end{array}$ \\
\hline [5.CP] & $\begin{array}{l}\text { - I think that's what drives some of the frustration probably from both } \\
\text { parties sitting at the far end is, you know, if we can't engage with the } \\
\text { customer how do we know we're delivering something that's going to } \\
\text { be beneficial ... because you've not got that direct communication the } \\
\text { frustration increases }\end{array}$ & $\begin{array}{l}\text { Software } \\
\text { Developer, } \\
\text { Software } \\
\text { Company }\end{array}$ \\
\hline \multirow[t]{4}{*}{ [6.MP] } & $\begin{array}{l}\text { - The expectations of the role of early adopter site in the NPfIT } \\
\text { implementation process was presented in official government } \\
\text { documents, e.g. in report by NHS Connecting for Health "Better } \\
\text { information better health NHS National Programme for IT Annual } \\
\text { Report 2004-2005": } \\
\text { - "Looking forward, our challenge over the coming year is to continue } \\
\text { to develop new systems and to roll out those systems which have } \\
\text { proven successful in early adopter sites. I am confident that our } \\
\text { Annual Report for 2005-2006 will contain details of our success in } \\
\text { delivering systems which will help tens of thousands of NHS personnel } \\
\text { to better serve millions of patients using tools which have been } \\
\text { delivered by NHS Connecting for Health." }\end{array}$ & $\begin{array}{l}\text { NHS } \\
\text { Connecting } \\
\text { for Health, } \\
(2005) \text { p. } 3^{24}\end{array}$ \\
\hline & $\begin{array}{l}\text { - Because a platform was created to learn from the places that got it } \\
\text { wrong and the places that got it right and to sort of use that as a } \\
\text { vehicle for securing trouble free deployment through the rest of the } \\
\text { program }\end{array}$ & $\begin{array}{l}\text { IT Manager, } \\
\text { Site } 2\end{array}$ \\
\hline & $\begin{array}{l}\text { - Once we had gone live with us then I thought, it's part of my job now } \\
\text { as a part of the NHS community to make sure other hospitals don't } \\
\text { suffer. I wasn't allowed to tell other hospitals how bad it was". }\end{array}$ & $\begin{array}{l}\text { Healthcare } \\
\text { Professional, } \\
\text { Site } 1\end{array}$ \\
\hline & $\begin{array}{l}\text { - We said right, you know, we've got three Trusts they all do it that way } \\
\text { you can't be that different, why don't you go and talk to them and find } \\
\text { out how they do it, and then the Trusts start, we started to have a kind } \\
\text { of meeting, we started to foster the meetings between the individual } \\
\text { organizations and it's much more effective. }\end{array}$ & $\begin{array}{l}\text { LSP } \\
\text { representative }\end{array}$ \\
\hline
\end{tabular}

${ }^{24}$ NHS Connecting for Health (2005) “Better information better health NHS National Programme for IT Annual Report 2004-2005”. 


\begin{tabular}{|c|c|c|}
\hline \multirow[t]{2}{*}[7.\mathrm{CP}]{} & $\begin{array}{l}\text { - “... our SHA chose two sites to be the first adopters of Cerner ... From } \\
\text { the trust perspective it felt very much it was decision outside of their } \\
\text { control }\end{array}$ & $\begin{array}{l}\text { IT Manager, } \\
\text { Site } 1\end{array}$ \\
\hline & $\begin{array}{l}\text { - I think you have to take the view that there was almost no choice in } \\
\text { taking on the system }\end{array}$ & $\begin{array}{l}\text { Healthcare } \\
\text { Professional, } \\
\text { Site } 2\end{array}$ \\
\hline \multirow[t]{2}{*}[8.\mathrm{CP}]{} & $\begin{array}{l}\text { - The system was perceived as being “...imposed rather than we had } \\
\text { willingly signed up to this. }\end{array}$ & $\begin{array}{l}\text { Healthcare } \\
\text { Professional, } \\
\text { Site } 1\end{array}$ \\
\hline & $\begin{array}{l}\text { - I think people have used it because they've had to and it's been, you } \\
\text { know, it's directive from the trust, and it's quite clear that that's what } \\
\text { we have to do and it would be, you know, you wouldn't be responding } \\
\text { to your work and what's been told of you if you didn't do it. }\end{array}$ & $\begin{array}{l}\text { Healthcare } \\
\text { Professional, } \\
\text { Site } 5\end{array}$ \\
\hline \multirow[t]{2}{*}{$\begin{array}{l}{[9 \text { A.CP }]} \\
\& \\
{[9 B \cdot N P]}\end{array}$} & $\begin{array}{l}\text { - Doctors have control to a large extent over what goes on in the trust } \\
\text { and they are very powerful and they like to do it their way.... They } \\
\text { easily circumvent the situation and they are able to do that, because } \\
\text { they just say, you can't question my professional judgment. }\end{array}$ & SHA Manager \\
\hline & $\begin{array}{l}\text { - The main issues for me from a clinical perspective is we had to do } \\
\text { business processes without a system, I'd never repeat that again and I } \\
\text { would say that to, I don't care who it would be, even if it was the chief } \\
\text { exec of the trust I would be saying you get me the product then, you } \\
\text { can influence, you get me the product and then I'll do it. Because } \\
\text { without that it's very hard to sell anything to clinicians. }\end{array}$ & $\begin{array}{l}\text { Healthcare } \\
\text { Professional / } \\
\text { Clinical Lead, } \\
\text { Site } 5\end{array}$ \\
\hline \multirow[t]{2}{*}{$\begin{array}{l}{[10 \mathrm{~A} . \mathrm{CP}]} \\
\& \\
{[10 \mathrm{~B} . \mathrm{CP}]}\end{array}$} & $\begin{array}{l}\text { - We are being pressured [by the LSP and CfH] into accepting } \\
\text { suboptimal things and they are being pressured to develop and deliver } \\
\text { suboptimal products just because of the type of pressure that they are } \\
\text { under. }\end{array}$ & $\begin{array}{l}\text { Healthcare } \\
\text { Professional, } \\
\text { Site } 2\end{array}$ \\
\hline & $\begin{array}{l}\text { - A lot of the time you know we, we raise an issue and it sits in the pot, } \\
\text { you're saying it's quite urgent. And then they'll come back and say oh } \\
\text { well actually here's a functional document that says well this system } \\
\text { works as designed. }\end{array}$ & $\begin{array}{l}\text { IT Specialist, } \\
\text { Site } 6\end{array}$ \\
\hline \multirow[t]{2}{*}{ [11A.CP] } & $\begin{array}{l}\text { - Connecting for Health can't force an NHS trust to take a system that } \\
\text { they don't want and when it comes to clinical systems they have this } \\
\text { red card they can wave called clinical risk, so any trust can just say oh } \\
\text { no it's too risky and there's almost nothing we can do about it, you } \\
\text { know, we could say oh really is it? }\end{array}$ & LSP Manager \\
\hline & $\begin{array}{l}\text { - The only control we have is to say, stop, this is unsafe. And that's } \\
\text { really the only control we have. That makes them jump. They will do } \\
\text { things }\end{array}$ & $\begin{array}{l}\text { Healthcare } \\
\text { Professional, } \\
\text { Site } 2\end{array}$ \\
\hline [11B.CP] & $\begin{array}{l}\text { - NLOP Board meeting minutes: "the product will not be accepted } \\
\text { unless it is deemed fit-for-purpose". }\end{array}$ & $\begin{array}{l}\text { NPfIT Local } \\
\text { Ownership } \\
\text { Program } \\
\text { (NLOP) }\end{array}$ \\
\hline [11C.CP] & $\begin{array}{l}\text { - Clinical safety trumps all cards and they play it whenever they fancy } \\
\text { it. So the way to get this stuff live is to work with the Trusts rather } \\
\text { than Connecting for Health and try and do what they need you to do. }\end{array}$ & LSP Manager \\
\hline [11D.CP] & $\begin{array}{l}\text { - ...you always get into the "I'm not going live unless you do this for } \\
\text { me" so regardless of the original intention the trust always have the } \\
\text { supplier over a barrel...(Interview). }\end{array}$ & $\begin{array}{l}\text { Software } \\
\text { Developer, } \\
\text { Software } \\
\text { Company }\end{array}$ \\
\hline
\end{tabular}




\begin{tabular}{|c|c|c|}
\hline [12.NP] & $\begin{array}{l}\text { - A clinical lead in one of the hospitals saw his job as "to try and } \\
\text { disseminate some information to our colleagues and allow it to filter } \\
\text { through that made them all realize that, look, the system is coming. We } \\
\text { haven't got a choice and we might as well make it work rather than } \\
\text { obstruct it, because at the end of the day, we've still got patients to } \\
\text { look after" (Interview). }\end{array}$ & $\begin{array}{l}\text { Healthcare } \\
\text { Professional, } \\
\text { Site } 2\end{array}$ \\
\hline [13.MP] & $\begin{array}{l}\text { - It was implicit in this report [NAO, 2008] that clinicians had } \\
\text { mobilized themselves into a powerful force where they could express } \\
\text { their concerns about the NPfIT and NCRS in particular. At the same } \\
\text { time, the British Medical Association had raised concerns about the } \\
\text { use of electronic records by GPs, particularly as patients had not been } \\
\text { consulted about plans to upload their summary data on the 'Spine' (a } \\
\text { centralized database). (Currie, 2012, p. 243) } \\
\text { - BMA advised doctors to boycott the NCRS and not to take part in } \\
\text { trials of Choose and Book system }\end{array}$ & $\begin{array}{l}\text { Sherriff } \\
(2004)^{25} \\
\text { Anonymous } \\
(2009)^{26}\end{array}$ \\
\hline [14.NP] & $\begin{array}{l}\text { - Normative pressures where isomorphic organizational change stems } \\
\text { from professionalism conspired to delegitimize the cultural acceptance } \\
\text { of the NPfIT among clinicians. Many hospital consultants and doctors } \\
\text { voiced serious disquiet that they had not been 'involved' in the } \\
\text { decision making about the NPfIT. They interpreted this as an affront to } \\
\text { their professional status and position, particularly in their role as the } \\
\text { guardians of patient safety. }\end{array}$ & $\begin{array}{l}\text { Currie, 2012, } \\
\text { p. } 242\end{array}$ \\
\hline \multirow[t]{2}{*}[15.\mathrm{CP}]{} & $\begin{array}{l}\text { - Article is a response to the Conservative Party commissioned report } \\
\text { on the future of IT in the NHS. } \\
\text { - From the Article: 'Shadow Health Minister Stephen O'Brien accepted } \\
\text { the recommendations of a review of the National Programme for IT } \\
\text { (NPfIT) by former British Computer Society chairman Dr Glyn Hayes. } \\
\text { The report said the national database was 'unnecessary' and 'has } \\
\text { caused extreme anxiety' about security.' }\end{array}$ & $\begin{array}{l}\text { Elledge, J } \\
(2009)^{27}\end{array}$ \\
\hline & $\begin{array}{l}\text { - Article notes, 'Aspects of the Summary Care Record will be reviewed } \\
\text { after doctors voiced concerns that patients were not being adequately } \\
\text { consulted and their medical notes were being uploaded without } \\
\text { consent. } \\
\text { - Ministers have written to the British Medical Association saying that, } \\
\text { while the Government agreed that patient records should be available } \\
\text { electronically, the process should be clearer for patients. The } \\
\text { Summary Care Record is being introduced nationally and each } \\
\text { primary care trust is writing to patients informing them that their } \\
\text { surgery is about to upload their records unless they opt out. }\end{array}$ & $\begin{array}{l}\text { Anonymous } \\
(2010)^{28}\end{array}$ \\
\hline
\end{tabular}

\footnotetext{
${ }^{25}$ Sherriff, L. (2004). BMA tells doctors: avoid NPfIT's flagship project: Patient data still at risk The Register 23 Nov. https://www.theregister.co.uk/2004/11/23/bma bpfit/. Last accessed 01/02/18.

${ }^{26}$ Anonymous (2009). BMA leader calls for NPfIT to be scrapped, Digital Health 3 rd June

https://www.digitalhealth.net/2009/o6/bma-leader-calls-for-npfit-to-be-scrapped/ Last accessed 01/02/18.

${ }_{27}$ Elledge (2009). Tories to scrap central NHS database. GP 21 August. https://www.gponline.com/tories-scrap-central-nhsdatabase/article/927463 (accessed 08/05/18).

${ }^{28}$ Anonymous (2010). Doctors' fears force review of online medical database. The Daily Telegraph, 15 Jun.
} 


\begin{tabular}{|c|c|c|}
\hline & $\begin{array}{l}\text { - There is some suggestion that concerns about confidentiality were } \\
\text { used by some doctors and the BMA as a cover for more self-interested } \\
\text { opposition (interview with Brennan, 2014), but it is doubtless that, on } \\
\text { the whole, the issue of confidentiality was a genuine concern that } \\
\text { attracted little government attention in the first half of the 1990s. [...] } \\
\text { The medical profession, however, refused to let the issue slide, with } \\
\text { the BMA engaging Ross Anderson of the University of Cambridge to } \\
\text { conduct a study into data security in clinical information system. }\end{array}$ & $\begin{array}{l}\text { Campion- } \\
\text { Awwad et al. } \\
(2014), \text { p. } 10\end{array}$ \\
\hline$[16 . \mathrm{CP}]$ & $\begin{array}{l}\text { - The article makes reference to Privacy International's description of } \\
\text { NPfIT as Britain's 'most appalling project'. }\end{array}$ & $\begin{array}{l}\text { Beckett, A } \\
(2009)^{29}\end{array}$ \\
\hline \multirow[t]{3}{*}[17.\mathrm{CP}]{} & $\begin{array}{l}\text { - The article states, "As the delays have built up, so has the impression } \\
\text { of a government IT scheme, like many before it, gradually sinking into } \\
\text { a swamp of technical difficulties, ethical disputes, incompetent } \\
\text { contractors and Whitehall over-ambition, and reckless spending." }\end{array}$ & $\begin{array}{l}\text { Beckett, A } \\
(2009)^{30}\end{array}$ \\
\hline & $\begin{array}{l}\text { - From the article, 'Further evidence has emerged over the findings of } \\
\text { Labour's most costly program, the mammoth £12.7bn IT scheme to } \\
\text { revolutionise the NHS. The Independent has learnt that just } 160 \text { health } \\
\text { organisations out of about 9,000 are using electronic patient records } \\
\text { under the scheme. The vast majority of those were GP practices. New } \\
\text { figures have also revealed that millions of pounds have been paid out } \\
\text { in legal fees. The tax payer has footed a £32.9, bill for "legal and } \\
\text { commercial support” for the National Programme for IT.' }\end{array}$ & $\begin{array}{l}\text { Savage, M } \\
(2010)^{31}\end{array}$ \\
\hline & $\begin{array}{l}\text { - Article notes, 'The rollout of the Summary Care Record has caused } \\
\text { such chaos at A\&E that the first hospital to gain access has had to } \\
\text { abandon plans for routine use of the system, Pulse can reveal. } \\
\text { - 'The ability for A\&E to access patient information held by GPs was } \\
\text { one of the main rationales for the introduction of the care record. } \\
\text { - 'But the document released by Connecting for Health's Summary Care } \\
\text { Record Advisory Group reveals Bolton hospital had to abandon plans } \\
\text { to access records except on the specific request of doctors and even } \\
\text { then by printing the hard copies.' }\end{array}$ & $\begin{array}{l}\text { Nowottny, S } \\
(2009)^{32}\end{array}$ \\
\hline$[18 . \mathrm{CP}]$ & $\begin{array}{l}\text { - Coercive pressures on CfH over the imposition of new systems on GP } \\
\text { practices procured as part of NPfIT. } \\
\text { - Objections raised included: [1] Under the terms of the General } \\
\text { Medical Services contract, which defines commissioning of GP } \\
\text { services, GP practices should have a choice over the system they use, } \\
\text { [2] The clinicians who use the system would become excluded from its } \\
\text { development, and [3] The products being offered under NPfIT were } \\
\text { still in development. }\end{array}$ & $\begin{array}{l}\text { Digitalhealth. } \\
\text { net }(2004 \\
\text { Sept } 02)^{33} \text {. }\end{array}$ \\
\hline
\end{tabular}

\footnotetext{
29 Beckett, A. (2009). System failure? The £12.7bn NHS computer programme is five years behind schedule and beset by criticism, viruses and fears over patient privacy: So should the world's biggest IT project be scrapped. The Guardian, 9 Jul, 10

${ }^{30}$ Beckett, A. (2009). System failure? The £12.7bn NHS computer programme is five years behind schedule and beset by criticism, viruses and fears over patient privacy: So should the world's biggest IT project be scrapped. The Guardian, 9 Jul, 10

${ }^{31}$ Savage, M. (2010). Labour's computer blunders cost £26bn: Ministers blamed for 'stupendous incompetence' after taxpayers left with huge bills for bungled projects. The Independent, 19 Jan, 4.

32 Nowottny, S. (2009). Care record: Care records rollout causes chaos in A \& E. Pulse, 4 Mar, 6.

33 Digitalhealth.net (2004). EMIS users urged to protest about systems choice. https://www.digitalhealth.net/2004/o9/emis-usersurged-to-protest-about-systems-choice/ (accessed 24/05/2018).
} 


\begin{tabular}{|c|c|c|}
\hline & $\begin{array}{l}\text { - GPs urged to campaign to retain their choice of system, rather than } \\
\text { adopt the as-yet untested CareCast system. CareCast was Fujitsu's } \\
\text { offer to GPs in the Southern cluster. }\end{array}$ & $\begin{array}{l}\text { Anonymous } \\
(2005)^{34}\end{array}$ \\
\hline & $\begin{array}{l}\text { - Announcement of the GP Systems of Choice (GPSoC) program, which } \\
\text { assures GP practices that they can choose from any system that has } \\
\text { accredited functionality. }\end{array}$ & $\begin{array}{l}\text { Arnott, S } \\
(2006)^{35}\end{array}$ \\
\hline [19.CP] & $\begin{array}{l}\text { - Our life is much harder since the SHAs came along, this is the local } \\
\text { ownership. So essentially a lot of the things that we would have been } \\
\text { able to get approved by Connecting for Health once, so let's say a } \\
\text { design document for example. So if we produce a design deliverable } \\
\text { for something originally Connecting for Health would have approved } \\
\text { that, so there would be one place, they would approve it on behalf it } \\
\text { all of the NHS in our cluster. We now have six discreet SHAs, each of } \\
\text { whom what to approve it and it's just a fact of life, but, you know, you } \\
\text { deliver a document to six SHAs who are autonomous organizations we } \\
\text { will get six times as many comments back, many of them will be } \\
\text { duplicated, not all of them. And so there is a role for Connecting for } \\
\text { Health there to act as coordinators and take some of that kind of pain } \\
\text { away by dealing on our behalf with this very, very diverse } \\
\text { organization. }\end{array}$ & LSP Manager \\
\hline
\end{tabular}

34 Anonymous (2005). GPs step up fight for choice of IT system. Pulse, 22 Jan, 7.

35 Arnott, S. (2006). GP surgeries to get choice of computer systems. Computing, 23 Mar, 5. 


\section{Appendix E: Comparison of Singapore and England Contexts}

\section{Table 7. Comparison of Singapore and England Contexts}

\begin{tabular}{|c|c|c|c|}
\hline Categories & & Singapore & England \\
\hline \multirow{3}{*}{$\begin{array}{l}\text { Institutional } \\
\text { characteristi } \\
\text { cs: } \\
\text { Context }\end{array}$} & Pop. 2011 & 5.2 Million & 52.6 Million \\
\hline & Area & $720 \mathrm{~km}^{2}$ & $130,265 \mathrm{~km}^{2}$ \\
\hline & $\begin{array}{l}\text { Structure of } \\
\text { Health Care } \\
\text { Provision }\end{array}$ & $\begin{array}{l}\text { Proportion of provision via socialized insurance: around } \\
34.24 \% \text { (Year } 2011 \text { ) of the total healthcare expenditure is } \\
\text { through government subsided or funded care } \\
\text { Total healthcare expenditure in } 2011-2.59 \% \text { of GDP and } \\
\text { USD } 1377.02 \text { per capita }{ }^{37} \\
\text { Public healthcare expenditure in } 2011-34.24 \% \text { of total and } \\
\text { USD } 471.49 \text { per capita }{ }^{20} \\
\text { Expenditure of NEHR Project from } 2010 \text { to } 2012 \text { (NEHR } \\
\text { Release } 1 \text { Implementation) - SGD } 109,699,803^{38} \\
\text { Expenditure of other IT project for NEHR (such as NHELP) } \\
\text { in } 2014 \text { - SGD } 2,088,670{ }^{39} \\
\text { Acute Care: Hospital provision is mainly through public } \\
\text { hospitals }(80 \%) \text {. } \\
\text { No. of hospitals in } 2011 \text { - public } 7 \text {, private } 7, \text { not-for-profit } \\
1 \text { ( 1:374000 per population) })^{40}\end{array}$ & $\begin{array}{l}\text { Proportion of provision via socialized insurance: } \\
\text { around } 83.3 \% \text { of healthcare expenditure is through } \\
\text { National Health Service (NHS) provided care }{ }^{43} \\
\text { Public healthcare expenditure (through NHS) in } \\
2011 \text { - } 83.3 \% \text { of total and GBP } 1939.16 \text { per capita } \\
\text { Expenditure of NPfIT at program close in } \\
\text { September } 2011 \text { - GBP } 6.4 \text { Billion } 44 \\
\text { Budget allocated to NPfIT from } 2004 \text { to } 2014 \text { - } \\
\text { GBP } 14.0 \text { Billion }{ }^{45} \\
\text { Acute Care: Hospital provision is mainly through } \\
\text { public hospitals with some services for the NHS } \\
\text { purchased from private providers. } \\
\text { No. of acute sites expected to receive NCRS - } 122 \\
(\sim 1: 431100 \text { per population })^{46}\end{array}$ \\
\hline
\end{tabular}

36 Index Mundi (2015). Singapore - Health Expenditure. https://www.indexmundi.com/facts/singapore/health-expenditure (accessed 24/05/2018)

37 MOF (2012). Expenditure Estimates by Head of Expenditure - Ministry of Health. https://www.singaporebudget.gov.sg/budget_2012/revenue_expenditure/attachment/35\%20MOH\%202012.pdf (accessed at 24/05/2018 $38 \mathrm{MOF}$ (2013). Expenditure Estimates by Head of Expenditure - Ministry of Health. https://www.singaporebudget.gov.sg/budget_2013/revenue_expenditure/attachment/35\%20MOH\%202013.pdf (accessed at 24/o5/2018) 39 MOF (2014). Expenditure Estimates by Head of Expenditure - Ministry of Health. https://www.singaporebudget.gov.sg/data/budget_2014/download/35\%20MOH\%202014.pdf (accessed at 24/05/2018)

40 Data.gov.sg (2018). Number of Acute Hospitals and Specialty Centres. https://data.gov.sg/dataset/number-of-acute-hospitals-and-specialty-centres?view_id=692502e2-2cfd-46be-9c9c-

fc66a243013f\&resource_id=04730f40-62ob-4c14-9bd7-1522dcogdde1 (accessed at 24/05//2018)

43 Commission on the Future of Health and Social Care in England (2014) The UK Private Health Market. The King's Fund: London.

44 DH (2011). Dismantling the National Programme for IT (Press Release: 22 Sept. 2011). London: Department of Health.

45 Comptroller and Auditor General (2011). The National Programme for IT in the NHS - An Update on the Delivery of Detailed Care Records Systems. London: The Stationery Office.

${ }^{46}$ Comptroller and Auditor General (2011). The National Programme for IT in the NHS - An Update on the Delivery of Detailed Care Records Systems. London: The Stationery Office. 


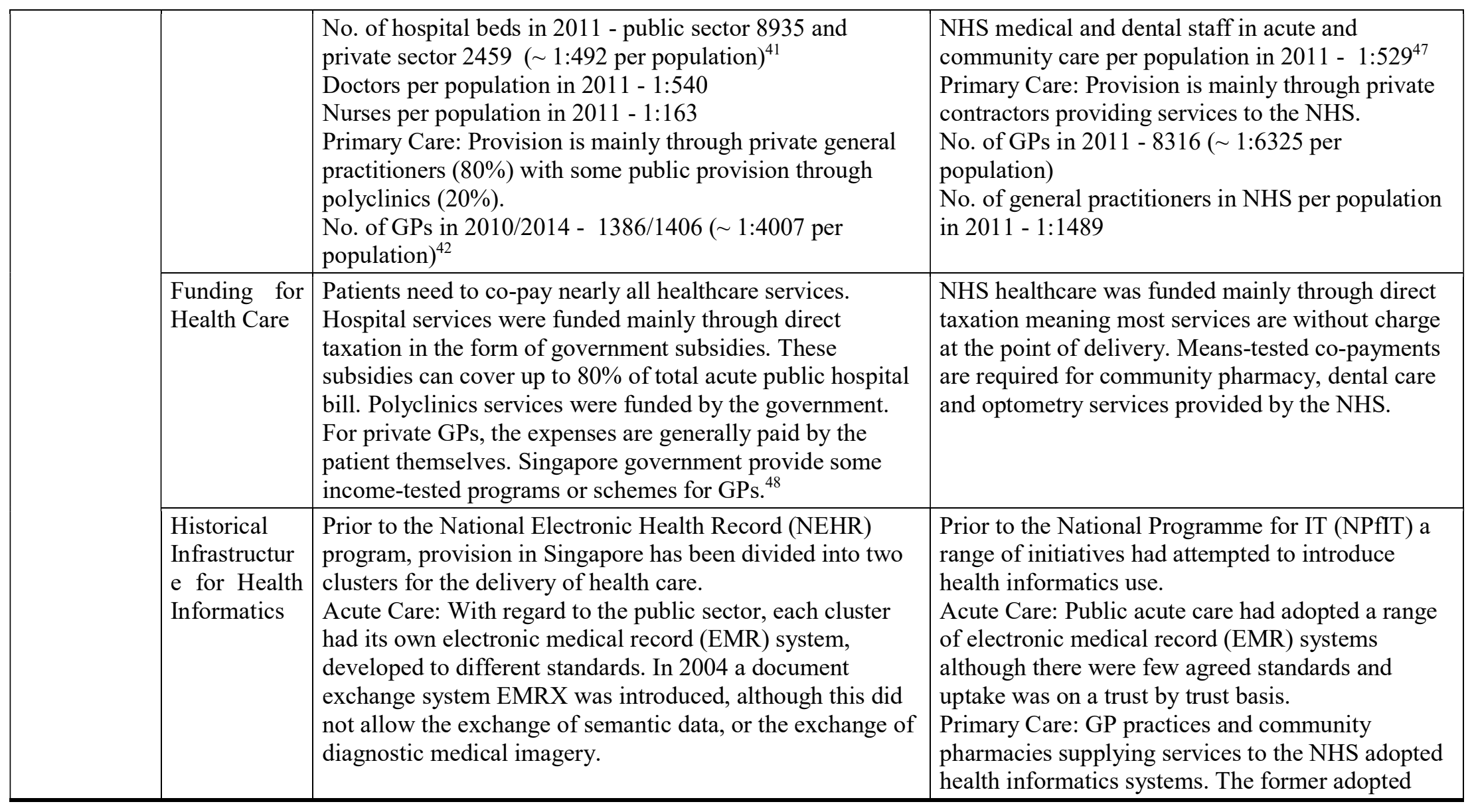

${ }_{41}$ Data.gov.sg (2018). Number of Hospital Beds. https://data.gov.sg/dataset/number-of-hospital-beds?view_id=59ec5f76-411b-42d7-9b8a6bceo8be1a65\&resource_id=9df79e72-a7ed-4df3-9a60-5fe434f38fe7 (accessed at 24/05/2018)

$42 \mathrm{MOH}$ (2013). Financing. https://www.moh.gov.sg/content/moh web/home/costs and financing/financing.html (accessed 24/05/2018) \& MOH (2014). Primary Care Survey 2014 Report. https://www.moh.gov.sg/content/moh_web/home/Publications/Reports/2017/primary-care-survey-2014-report.html (accessed 24/05/2018)

47 The Health and Social Care Information Centre. NHS Workforce: Summary of Staff in the NHS: Results from September 2011. Leeds, UK: The Health and Social Care Information Centre; 2012.

${ }^{48} \mathrm{MOH}$ (2015). Medisave for Chronic Disease Management Programme (CDMP) and vaccinations. https://www.moh.gov.sg/content/moh_web/home/policies-andissues/elderly_healthcare.html (accessed 24/05/2018) 


\begin{tabular}{|c|c|c|c|}
\hline & & $\begin{array}{l}\text { Primary Care: In the private sector there was limited } \\
\text { adoption of EMR systems (less than } 30 \% \text { by 2014). }\end{array}$ & $\begin{array}{l}\text { electronic health records (EHRs) to meet } \\
\text { contractual changes with state subsidies promoting } \\
\text { system use, the latter driven by stock control and } \\
\text { patient record keeping requirements. }\end{array}$ \\
\hline \multirow[t]{2}{*}{$\begin{array}{l}\text { Project } \\
\text { Organization }\end{array}$} & $\begin{array}{l}\text { Organizatio } \\
\text { nal } \\
\text { Landscape } \\
\text { and } \\
\text { Stakeholder } \\
\text { s in System } \\
\text { Delivery }\end{array}$ & $\begin{array}{l}\text { The Ministry of Health (MOH) was responsible for setting } \\
\text { policies of NEHR. } \\
\text { Ministry of Health Holdings (MOHH) undertook NEHR } \\
\text { project management on behalf of MOH. It defined the } \\
\text { architecture of NEHR and was responsible for the delivery } \\
\text { of NEHR, which was supported by IHIS and Accenture-led } \\
\text { consortium. } \\
\text { Integrated Health Information System (IHIS) is a subsidiary } \\
\text { of MOHH and worked with the IT teams from MOHH in } \\
\text { the integration of different IT systems and NEHR. It } \\
\text { focused on a technical perspective, and extracted, } \\
\text { transformed and mapped relevant data for NEHR database. } \\
\text { IHIS also worked with IT vendors and commercial solution } \\
\text { providers (i.e., Accenture-led consortium). The NEHR } \\
\text { systems and the infrastructure were developed and } \\
\text { deployed by the commercial solution providers. They are } \\
\text { also responsible for the integration of the legacy systems } \\
\text { and NEHR systems. }\end{array}$ & $\begin{array}{l}\text { The Department of Health (DH) was responsible } \\
\text { for national policy which included NPfIT, and for } \\
\text { on health and social care. Below DH, Strategic } \\
\text { Health Authorities (SHAs) provided regional } \\
\text { oversight and commissioned capital expenditure } \\
\text { projects. Local Primary Care Trusts (PCTs) were } \\
\text { responsible for local commissioning of services. } \\
\text { DH created Connecting for Health (CfH) to } \\
\text { provide an arms-length body to commission and } \\
\text { assure local and national NPfIT services provided } \\
\text { by health information system suppliers. National } \\
\text { services included a national network for data } \\
\text { exchange and the creation of services for a national } \\
\text { Summary Care Record (SCR) amongst others. } \\
\text { Originally, NPfIT solutions for acute and primary } \\
\text { care were delivered by regional Local Service } \\
\text { Providers. These would be abolished and replaced } \\
\text { by SHAs and PCTs in the National Local } \\
\text { Ownership Program. SHAs were responsible for } \\
\text { acute care health informatics, PCTs for primary } \\
\text { care. }\end{array}$ \\
\hline & $\begin{array}{l}\text { Delivery } \\
\text { Agencies for } \\
\text { Health } \\
\text { Informatics }\end{array}$ & $\begin{array}{l}\text { There was a steering committee (Clinical Advisory Group) } \\
\text { co-chaired by MOHH CIO that looked after various NEHR } \\
\text { clinical informatics alongside the governance aspects. IHIS } \\
\text { also had the task of supporting the creation of a } \\
\text { consolidated, strengthened health informatics workforce } \\
\text { since it worked with MOHH in the standardization of } \\
\text { clinical information. Accenture-led consortium worked } \\
\text { with MOHH for NEHR solution development, which } \\
\text { included technical, clinical and information governance. }\end{array}$ & $\begin{array}{l}\text { Connecting for Health (CfH) was responsible for } \\
\text { commissioning NPfIT's national architecture, for } \\
\text { procurement of systems at national and regional } \\
\text { level, and for assuring that systems met expected } \\
\text { standards. Systems were provided by private sector } \\
\text { companies. The Health and Social Care } \\
\text { Information Centre (HSCIC) was responsible for } \\
\text { developing data standards whilst Strategic Health } \\
\text { Authorities (SHAs) took responsibility for regional } \\
\text { delivery. }\end{array}$ \\
\hline
\end{tabular}




\begin{tabular}{|c|c|c|c|}
\hline & $\begin{array}{l}\text { Funding } \\
\text { arrangement } \\
\text { s/incentives }\end{array}$ & $\begin{array}{l}\text { Funding Source: MOH and MOHH provided all funding } \\
\text { for delivery and implementation of the NEHR systems. } \\
\text { MOHH had offset NEHR costs from the start till it went } \\
\text { live in April } 2011 \text {. } \\
\text { Acute Care: NEHR systems and their integration with } \\
\text { current EMR systems were provided without charge for } \\
\text { sites through the solution providers. Suppliers received } \\
\text { funding for reaching development milestones. } \\
\text { Primary Care: Community hospital and polyclinics were } \\
\text { integrated without charge. However, though the NEHR } \\
\text { system and the integration was free, GP clinics and nursing } \\
\text { homes did not get full financial support for IT infrastructure } \\
\text { to connect to NEHR. }\end{array}$ & $\begin{array}{l}\text { Funding Source: DH provided all funding for } \\
\text { delivery and implementation of new systems, and } \\
\text { for upgrading of existing systems. } \\
\text { Acute Care: Systems provided without charge for } \\
\text { sites through the LSP. Suppliers received funding } \\
\text { for reaching development milestones. } \\
\text { Primary Care: Systems procured by PCTs for GP } \\
\text { practices. Community pharmacies received DH } \\
\text { payment to upgrade. Suppliers received money } \\
\text { from contracts with PCTs or sites. }\end{array}$ \\
\hline & $\begin{array}{l}\text { Contract and } \\
\text { Delivery } \\
\text { Monitoring }\end{array}$ & $\begin{array}{l}\text { MOHH was responsible for monitoring the implementation } \\
\text { of NEHR and it needed to report the progress regularly to } \\
\text { MOH. }\end{array}$ & $\begin{array}{l}\text { CfH was initially responsible for oversight of } \\
\text { contracts, then SHAs as part of NLOP } \\
\text { arrangements. }\end{array}$ \\
\hline \multirow[t]{2}{*}{$\begin{array}{l}\text { Delivery of } \\
\text { systems }\end{array}$} & $\begin{array}{l}\text { Design } \\
\text { Choices in } \\
\text { Planned } \\
\text { Systems and } \\
\text { Services }\end{array}$ & $\begin{array}{l}\text { NEHR system was developed with a centralized database, } \\
\text { which could be accessed through the integrated entry or } \\
\text { online Web portal. New IT infrastructure was also } \\
\text { developed for its connection. } \\
\text { Acute Care: Existing EMR systems were integrated with } \\
\text { the new NEHR system. Existing data exchange system } \\
\text { EMRX was replaced. Daily summary records are pushed } \\
\text { into NEHR system. } \\
\text { Primary Care: The MOH-funded systems (such as } \\
\text { GPConnect for GP clinics and NHELP for nursing homes) } \\
\text { are linked with NEHR system. }\end{array}$ & $\begin{array}{l}\text { NPfIT was developed around a National Network } \\
\text { for the NHS (N3) and a set of centralized Spine } \\
\text { services. Only systems with CfH accredited } \\
\text { functionality were allowed to connect to N3 and } \\
\text { exchange data with the Spine. } \\
\text { Acute Care: Existing EMR systems were to be } \\
\text { replaced with new systems provided by contractors } \\
\text { for NPfIT. The new EMR systems would have } \\
\text { access to Spine services. } \\
\text { Primary Care: Spine service functionality added to } \\
\text { existing systems. A daily extract from GP practice } \\
\text { EHR systems would form the basis of a Spine } \\
\text { hosted Summary Care Record, accessible across } \\
\text { the NHS. } \\
\text { Social Care and Child Protection: Areas not } \\
\text { considered in scope for NPfIT. }\end{array}$ \\
\hline & $\begin{array}{l}\text { Processes } \\
\text { Deployed in } \\
\text { System }\end{array}$ & $\begin{array}{l}\text { Acute Care: Top-down implementation model with NEHR } \\
\text { system provided by commercial solution providers for } \\
\text { public sector acute and community hospitals. Supplemented }\end{array}$ & $\begin{array}{l}\text { Acute Care: Top-down delivery model with } \\
\text { information systems supplied by LSPs. } \\
\text { Supplemented by bottom-up design efforts through } \\
\text { inter-health care trust meetings. }\end{array}$ \\
\hline
\end{tabular}




\begin{tabular}{|c|c|c|c|}
\hline & $\begin{array}{l}\text { Implementat } \\
\text { ion }\end{array}$ & $\begin{array}{l}\text { by bottom-up design efforts through consultations, CMIOs } \\
\text { and workforce groups. } \\
\text { Primary Care: Top-down implementation model with "soft } \\
\text { approaches", such as IT-enable programs and funding. }\end{array}$ & $\begin{array}{l}\text { Primary Care: Bottom-up adoption of services } \\
\text { provided as part of existing primary care } \\
\text { information systems. }\end{array}$ \\
\hline & $\begin{array}{l}\text { Resources } \\
\text { Available }\end{array}$ & $\begin{array}{l}\text { Primary Care: MOH set aside a budget of S\$20 million for } \\
\text { an Early Contribution Incentive (for GPs and nursing } \\
\text { homes to encourage the early contribution of data to NEHR } \\
\text { from GP clinics and nursing homes. }{ }^{49} \text { In addition, there } \\
\text { exist IT-enabled programs (such as CLEO/GP Connect for } \\
\text { GP clinics and NHELP for nursing homes), which provide } \\
\text { IT infrastructure at a low cost and integrate the links to } \\
\text { NEHR and other public healthcare resources. }{ }^{50}\end{array}$ & $\begin{array}{l}\text { Acute Care: a Deployment Incentive Fund of } £ 1 \\
\text { million per site was available for early adopter } \\
\text { sites for Care Records Service adoption. } \\
\text { Primary Care: technical and business process } \\
\text { support was made available by CfH to support the } \\
\text { early adopters of new primary care information } \\
\text { services. }\end{array}$ \\
\hline Outcomes & & $\begin{array}{l}\text { By the middle of } 2012 \text { (at the end of NEHR Phase } 2 \text { ), } \\
\text { NEHR completed Phase } 1 \text { mostly on time by achieving its } \\
\text { initial scope of involving all public-sector healthcare } \\
\text { institutes, } 6 \text { community hospitals, } 2 \text { nursing homes, the } \\
\text { armed forces and } 50 \text { GPs (Hui, 2012). } \\
\text { By March of 2013: The system has been rolled out to } \\
\text { almost } 5000 \text { clinical users in the public healthcare sector, } \\
\text { including } 8 \text { hospitals, } 6 \text { specialty centres, and all } \\
\text { polyclinics. }\end{array}$ & $\begin{array}{l}\text { At the close of NPfIT in } 2011,19 \text { of the } 122 \text { acute } \\
\text { sites }(15.6 \%) \text {, GP sites in } 10 \% \text { NHS organizations, } \\
44 \text { of the } 90 \text { community healthcare sites }(48.9 \%) \\
\text { and } 21 \text { of } 56 \text { mental health care sites }(37.5 \%) \text { that } \\
\text { were expected to adopt NCRS, had done so. } \\
\text { Although the NPfIT program has closed the } \\
\text { national infrastructures identifying patients, } \\
\text { transmitting prescriptions and sharing SCR data } \\
\text { remains. A range of new funds have been created } \\
\text { to support adoption of EMR systems into acute } \\
\text { care, and to contribute to a new Integrated Digital } \\
\text { Care Record. }\end{array}$ \\
\hline
\end{tabular}

49 IHIS (2017). For Immediate Release - Early Contribution Incentive for Healthcare Licensees. https://www.his.com.sg/Latest_News/Media_Releases/Documents/2017\%20Media\%20Releases/Factsheet\%20\%20ECI\%20(as\%20of\%208\%20Nov).pdf (accessed 24/05/2018)

${ }^{\circ} \mathrm{MOH}$ (2018). Contributing Data to the NEHR

https://www.moh.gov.sg/content/dam/moh_web/HCSA/Docu/MOH\%20P2\%20Consult\%20Session\%20NEHR_vo.11.pdf (accessed 24/o5/2018)

${ }^{51}$ Comptroller and Auditor General (2011). The National Programme for IT in the NHS - An Update on the Delivery of Detailed Care Records Systems. London: The Stationery Office. 